\title{
The Representation of Peripheral Nerve Inputs in the S-I Hindpaw Cortex of Rats Raised with Incompletely Innervated Hindpaws
}

\author{
J. T. Wall and C. G. Cusick' \\ Department of Psychology, Vanderbilt University, Nashville, Tennessee 37240
}

The hindpaws of 1-d-old rats were partially denervated by transection and ligation of the sciatic nerve. Following growth to adulthood, the topographical organization of the hindpaw representation in primary somatosensory (S-I) cortex was studied with neurophysiological mapping techniques and compared to the organization of previously studied normal adult rats and adult rats that had sciatic transection. The goals were (1) to determine how the topographical organization of the hindpaw representation is affected when development occurs with an incomplete set of peripheral inputs, and (2) to identify possible differences in the capacity of neonatal and adult CNSs to adjust to loss of inputs.

The rat hindpaw is relatively immature on the day of birth. Neonatal transection and ligation of the sciatic nerve stunted gross development of the hindpaw and resulted in a permanent loss of low-threshold mechanoreceptor inputs from hindpaw zones normally innervated by the sciatic nerve.

A comparison of the cortical representations of neonatally denervated and normal rats indicated that early loss of sciatic inputs caused several changes in the topographical organization of the hindpaw cortex, including (1) a loss of the representation of hindpaw skin areas innervated by the sciatic nerve, (2) a limited infringement of cutaneous inputs from the hindquarter into the cortical zone deprived of sciatic hindpaw inputs, (3) increased variability in the topographical relationships of the hindpaw and hindquarter representations, and (4) a decrease in the size of the cortical area responsive to cutaneous inputs.

A comparison of the cortical representations of neonatal and adult denervates indicated that the general cortical reaction to sciatic injury at both ages was similar: Neurons in some parts of the deprived hindpaw cortex were activated by cutaneous inputs from uninjured nerves, whereas neurons in other parts of this cortex were unresponsive to cutaneous stimulation. The topographical organization and size of projection zones of uninjured peripheral inputs were different, however, after denervation in neonatal and adult rats.

From these findings we suggest that (1) development of a normal, topographically organized hindpaw representation requires integration of hindpaw inputs in a spatially specific manner, (2) more than one pattern of cortical adjustment occurs after sciatic injury, and age is an important determinant of the pattern that is established, and (3) different mechanisms of central adjustment underlie age-related differences in cortical pat-

\footnotetext{
Received July 8, 1985; revised Sept. 16, 1985; accepted Sept. 23, 1985.
}

We thank Drs. Michael Huerta, Jon Kaas, and Michael Sesma for thoughtful criticisms of the manuscript. We also thank Dr. James A. McKanna for the use of his Bioquant II Image Analysis Systcm. This work was supported by Grant BNS-8205745.

Correspondence should be addressed to Dr. John T. Wall, Department of Psychology, Vanderbilt University, Nashville, TN 37240.

C. G. Cusick's present address: Department of Anatomy, Tulane University Medical Center, New Orleans, LA 70112.

Copyright $(1986$ Society for Neuroscience $0270-6474 / 86 / 041129-19 \$ 02.00 / 0$ terns, i.e., changes after neonatal injury involve disruption of the initial development of ascending hindpaw projections, whereas changes after adult injury involve functional alterations in pre-existing connections.

The hindpaw skin of the rat is innervated by low-threshold mechanosensory fibers from the saphenous and sciatic nerves. The ascending central connections of these nerves project to the primary somatosensory (S-I) cortex to form a representation of the hindpaw skin (Chapin and Lin, 1984; Donoghue et al., 1979; Hall and Lindholm, 1974; Sapienza et al., 1981; Wall and Cusick, 1984; Welker, 1971, 1976; Woolsey, 1958). Normally, there is a high degree of spatial order in this projection system, and the location, size, and internal topographical organization of the hindpaw representation and of the sciatic and saphenous subcomponents of this representation are similar from animal to animal (e.g., Fig. 1, $A, B$; Wall and Cusick, 1984).

Cortical organizational patterns in adult mammals are initially established during development. In the somatosensory system of rodents, the initial assembly of ascending projections between the skin and S-I cortex normally continues into the first postnatal week. Peripheral injury during this time disrupts the development of these projections (e.g., Erzurumlu and Killackey, 1982; Jeanmonod et al., 1981; Pidoux et al., 1980; Rhoades et al., 1983; Simons et al., 1984; Waite, 1984). The first goal of the present study was to compare spatial features of the hindpaw representation in normal adult rats (e.g., Fig. $1 B$ ) with those in adult rats whose hindpaws were partially denervated by sciatic nerve transection on the day of birth. The question of interest was, how is the normal topographical organization of the S-I hindpaw cortex altered when postnatal development occurs with an incomplete set of peripheral inputs? This issue is relevant for understanding developmental factors that are important for normal spatial assembly of topographically organized cortical representations.

Under normal conditions, the cortical organizational features that are established during development are presumably maintained with some degree of stability during adulthood. Recent studies indicate, however, that when the hindpaws of adult rats are partially deafferented by transection of the sciatic nerve, the spatial organization of the S-I hindpaw representation is changed in two major ways (Wall and Cusick, 1984). First, because of the loss of peripheral inputs, the cortical representation of the sciatic skin is lost (e.g., Fig. 1C). Second, the representation of saphenous inputs from the hindpaw expands and occupies parts of the hindpaw cortex that would normally represent lost sciatic inputs. This expansion of the saphenous representation appears to have limitations, since other cortical regions that would normally represent sciatic inputs remain unresponsive to cutaneous inputs even after chronic deafferentation. In view of these findings, the second goal of the present study was to test whether the cortical changes after adult injury (e.g., Fig. 1C) are representative of the cortical effects of injury at an earlier age. In 


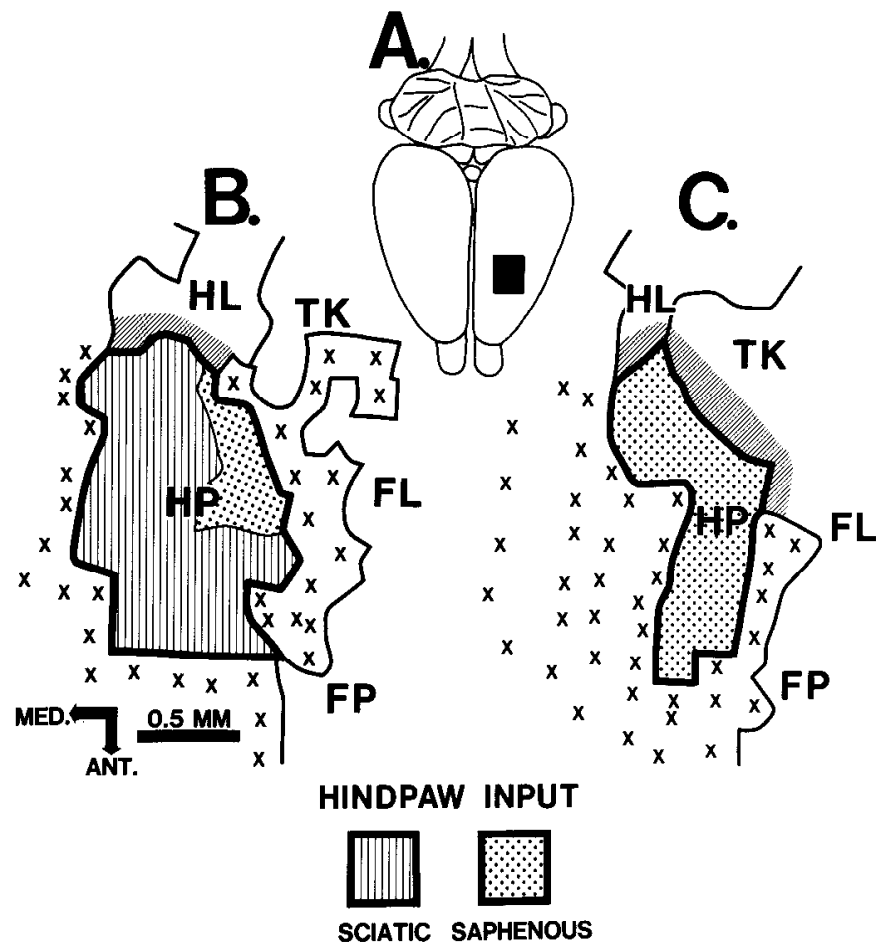

Figure 1. Representation of cutaneous mechanoreceptor inputs from the hindpaw and adjacent skin regions in the primary somatosensory (S-I) cortex of the rat. $A$, Dorsal view of the rat brain showing the approximate location of the hindpaw representation (black rectangle). $B$, The topographical organization of the S-I representation of the hindpaw $(H P)$, hindlimb $(H L)$, trunk $(T K)$, forelimb $(F L)$, and forepaw $(F P)$, as determined with neurophysiological mapping techniques in a normal adult rat. The hindpaw representation (thick border) is normally linked to the remaining body map along its caudal border (diagonal hatching) with the hindlimb representation. Most of the lateral, rostral, and medial border of the hindpaw representation is adjacent to cortical regions that are not responsive to cutaneous stimuli ( $X$ 's). The hindpaw skin is normally innervated by the sciatic and saphenous nerves, each of which has its own skin field on the hindpaw. In cortex, the hindpaw representation is internally organized and the skin field of each nerve activates the indicated part of the hindpaw representation. $C$, The S-I representation of low-threshold inputs from the hindpaw and adjacent body parts in an adult rat that had undergone transection and ligation of the sciatic nerve during adulthood. Note the loss of representation of sciatic inputs from the hindpaw and the enlargement of the representation of saphenous inputs from the hindpaw. Abbreviations, spatial calibration, and orientation as in $B$.

particular, does the S-I representation of saphenous inputs from the hindpaws of adult rats that had neonatal sciatic transection show the same degree of expansion seen in rats denervated during adulthood, or does "plasticity" of connections or some other feature of the developing system lead to a different result? This issue is important for understanding possible differences in the central capacity of young and adult systems to adjust after nerve injury.

\section{Materials and Methods}

The right hindpaws of 13 Sprague-Dawley rat pups (both sexes) were partially denervated by transection of the sciatic nerve on the day of birth. After reaching adulthood (109-489 d, mean $-234 \mathrm{~d})$, the grown pups were used in one of two experiments. In 11 rats, neurophysiological mapping procedures were used to study the contralateral S-I hindpaw representation. In the two remaining rats, axonal recordings were used to study the peripheral innervation of the denervated and normal hindpaws directly and thus to corroborate findings from the cortical studies.

\section{Neonatal denervation}

Within the first $24 \mathrm{hr}$ after birth, rat pups were removed from their mothers and anesthetized with ether. The hindpaw of the rat is in a highly immature stage of development on the day of birth. For example, the small hairs on the dorsal surface of the hindpaw, which are highly sensitive to tactile stimuli in the adult, have not emerged from their folliclcs and arc not visible at birth; in addition, the pads on the plantar skin are poorly defined, and the toes are still largely fused and do not appear as independent appendages. Local anesthetic ( $5 \%$ Xylocaine) was applied to the hindlimb and an incision was made across the lateral surface of the thigh and calf. Under microscopic view, the sciatic nerve was isolated from the surrounding thigh muscles and one to three ligatures were tightly tied around the nerve between the sciatic notch and the knee. The nerve was then transected distal to the ligatures and the distal segment of the nerve was stripped to the calf. Two approaches were used to prevent subsequent regeneration of the nerve. In most rats $(64 \%)$, the hindlimb was reopened once or twice at periods of between 29 and $208 \mathrm{~d}$ after the original denervation and the proximal sciatic stump was examined. The transected nerves were smaller than normal and, rather than having a normal shiny white appearance, were gray, apparcntly owing to dccreascd myelination. The ligatures were usually still in position and the stumps appeared to end in neuromas that were embedded in scar tissue around muscles. During examinations, we adopted the procedure of cutting the scar tissue from the surrounding muscles and religating the nerve stumps near the scar tissue-neuroma mass. In the remaining rats, the ligated nerve stump was embedded in a dental acrylic tube at the time of denervation. Observations from dissections of the hindlimb after mapping and from the locations of receptive fields recorded during the experiments indicate that each of these approaches successfully prevented sciatic fibers from reinnervating the denervated skin on the leg and hindpaw. As is described in Results, the proximal stumps of three rats were resectioned immediately prior to cortical mapping as a further test for regeneration, and the results from these experiments also indicate that the above precautions were successful in preventing regeneration of the sciatic nerve.

Following hindlimb operations, skin incisions were closed with suture and treated with local anesthetic. All rats were housed in cages with smooth plastic floors and adequate litter from the time of nerve injury until the experiment was ended to prevent further injury of the hindpaw.

\section{Cortical mapping}

The mapping procedures were similar to those used in previous studies of normal rats and rats denervated in adulthood (Wall and Cusick, 1984). Animals were anesthetized with ketamine hydrochloride (50-75 $\mathrm{mg} / \mathrm{kg}, \mathrm{IM}$ ) and maintained with supplemental injections as needed. The ear canals were locally anesthetized ( $5 \%$ Xylocaine) and the head was positioned in a stereotaxic frame. The animal was placed on a hot water pad and rectal temperature was maintained at around $37^{\circ} \mathrm{C}$. A craniotomy was made over one hemisphere and a cylinder was mounted on the skull. The dura was reflected, the brain was covered with silicone, and a magnified photograph $(\times 25-30)$ was made of the cortical surface.

A gridlike array of penetrations (80-100 per rat) was spaced across the medial extent of the S-I cortex. Penetrations were made with tungsten microelectrodes (1-4 M $\Omega$, measured at $1 \mathrm{kHz}$ ) oriented perpendicular to the cortical surface. The microelectrode was viewed through a dissecting microscope and the point of entry for each penetration was carefully marked on the brain photograph. Depending on the surface vasculature, efforts were made to space penetrations $150-200 \mu \mathrm{m}$ apart. Using conventional techniques for recording neural activity, the microelectrode was advanced until multiple unit responses to stimulation of the skin and hairs were maximized on an audiomonitor. The most brisk responses were usually recorded at microdrive readings of 500 $800 \mu \mathrm{m}$ below the surface. Cutaneous receptive fields were defined with hand-held probes and marked on drawings of the body surface. In penetrations where no evoked cutaneous responses were observed, efforts were made to stimulate wide regions of the body surface as the electrode was advanced into and withdrawn from depths below those that were normally responsive.

To analyze the results, receptive field locations were related to each penetration site. A two-dimensional representation of the hindpaw and adjacent skin surface was then reconstructed by delimiting cortical regions with receptive fields at identified skin locations. Borders between cortical representations of different body locations were established midway between adjacent penetrations with receptive fields on different body locations. If the receptive field of a penetration equally straddled skin parts that were being distinguished, the border separating the in- 


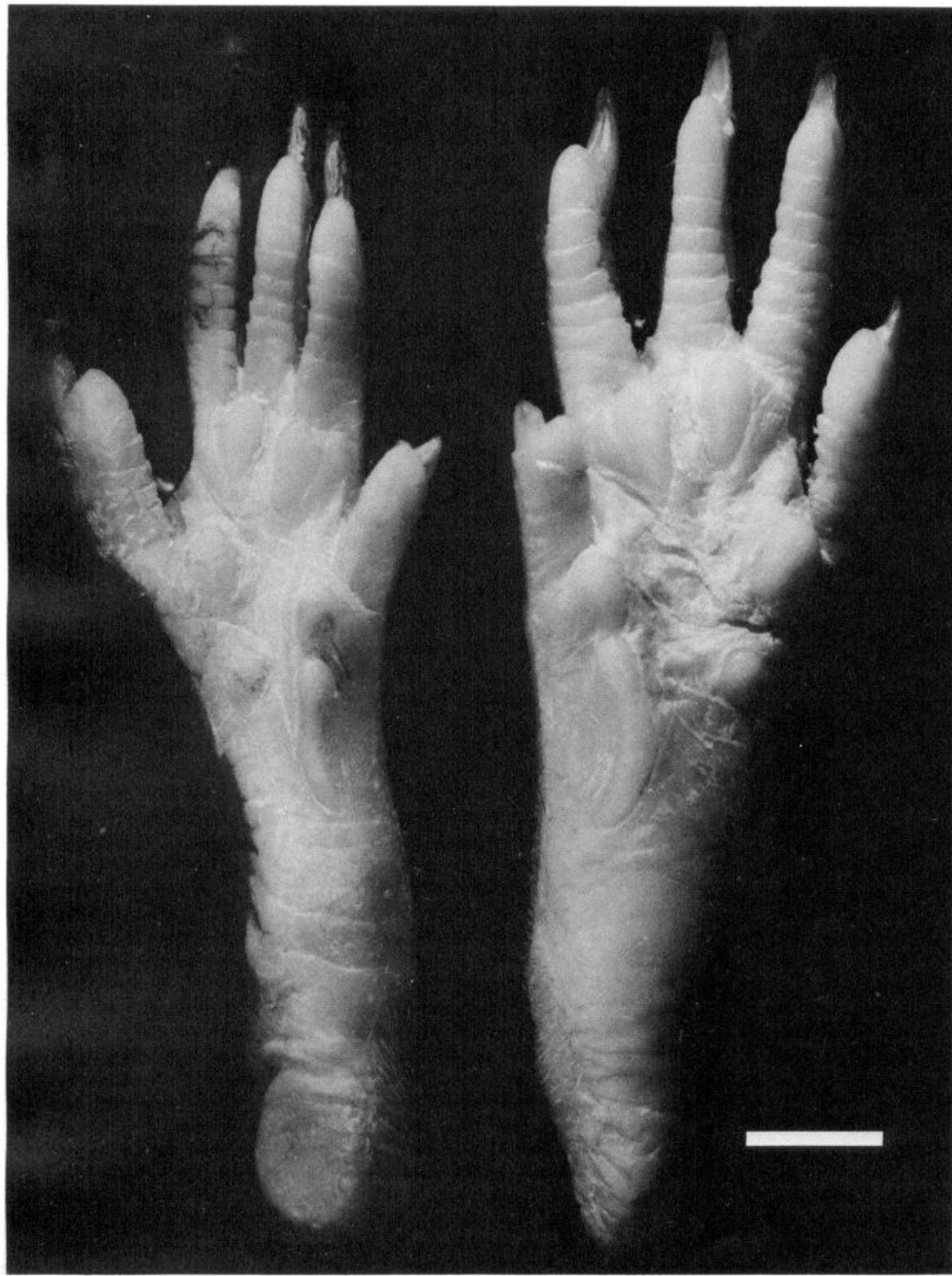

Figure 2. Photograph of the plantar surfaces of the denervated (left) and normal (right) hindpaws of an adult rat that had undergone transection and ligation of the sciatic nerve on the day of birth. Note the obvious difference in the size of the denervated hindpaw. Calibration bar, $0.5 \mathrm{~cm}$.

volved cortical representations was placed at the penetration position. Borders between cutaneous representations and cortical areas not responsive to cutaneous stimuli were established midway between responsive and adjacent nonresponsive penetration locations. Using these borders, the cortical areas representing inputs from the hindpaw and other skin regions were measured with a computerized planimeter system (Bioquant II, Image Analysis System; E. Leitz). Where appropriate, cortical area measurements from neonatal denervates have been compared with measurements from normal rats or adult denervates (Wall and Cusick, 1984). Cortical areas in all groups were derived with identical procedures.

All cortical mapping studies were carried out by two investigators. Movement of the electrode and recording of penetration locations were performed by one investigator, while the second defined and recorded receptive fields. In all experiments the investigator mapping receptive fields neither saw the brain photograph nor knew the location of the microelectrode. In some experiments, neonatally denervated rats were mixed with rats in other experimental groups as a further "blind" precaution.

\section{Nerve recording}

The skin territory innervated by low-threshold mechanoreceptor afferents of the saphenous nerve was defined in two rats with nerve recordings. The animals were anesthetized with ketamine hydrochloride (50$75 \mathrm{mg} / \mathrm{kg}$, IM) and the hindlimbs were mounted in a position that allowed access to the hindpaw. The saphenous nerve was cut at the thigh and an attempt was made to define a receptive field from multiple fiber activity, while the whole nerve was impaled through the cut end with a tungsten microelectrode. The epineurium was then split and fascicles were recorded individually. Finally, each fascicle was dissected and recordings were made from small strands of fibers. The end of the nerve was then trimmed off and the procedure reiterated until all branches of the saphenous nerve had been sampled repeatedly, down to the ankle. Near the ankle, the branches of the saphenous nerve are small and recordings gave very brisk responses which allowed clear delineation of receptive field boundaries. Receptive fields were defined with tactile stimuli similar to those used for the cortical studies and were recorded on line drawings of the hindpaw. 


\section{NORMAL}

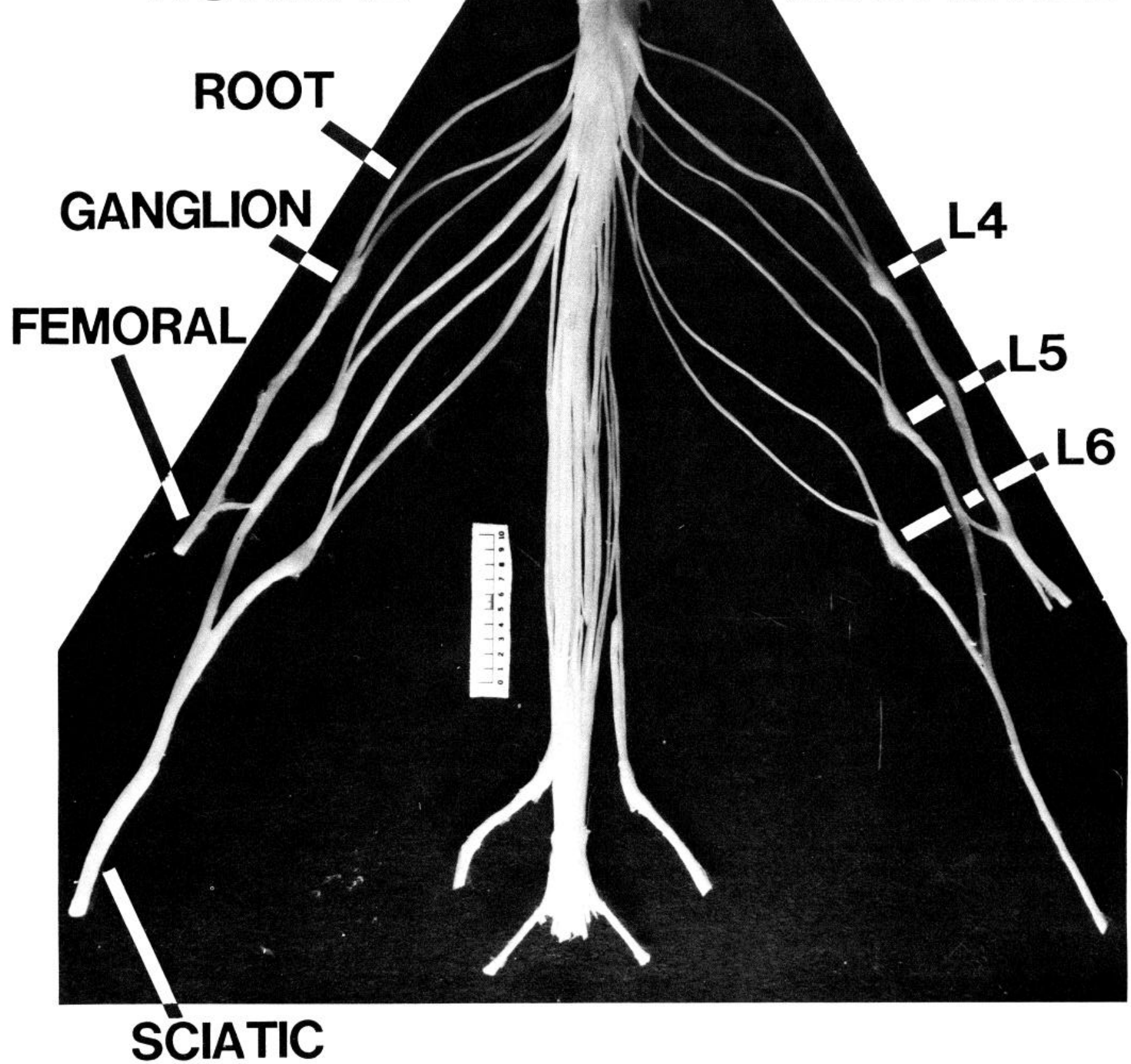

Figure 3. Photograph of a dissection of the sciatic nerve and related dorsal root ganglia and roots from the $\mathrm{L}_{4}-\mathrm{L}_{6}$ spinal segments of an adult rat that had undergone unilateral transection and ligation of the sciatic nerve on the day of birth. The $\mathrm{L}_{4}$ ganglia and roots also contain neurons of the femoral nerve. Note the diminished size of the sciatic nerve and $\mathrm{L}_{5}-\mathrm{L}_{6}$ ganglia and roots on the side that had undergone transection. Some branches not directly related to the sciatic nerve (e.g., a branch to $\mathrm{L}_{3}$ from the femoral nerve) are not shown. Calibration bar, $10 \mathrm{~mm}$.

\section{Results}

The functional organization of the S-I hindpaw cortex and the peripheral innervation of the hindpaw were studied in adult rats whose hindpaws had been partially denervated by sciatic nerve transection on the day of birth. These results were then compared to similar data from normal rats and from rats that had undergone sciatic nerve transection during adulthood (Wall and Cusick, 1984).

\section{Changes in the hindlimb after neonatal denervation}

Neonatal sciatic transection resulted in an obvious retardation in the development of the hindpaw and in an abnormal use of the hindlimb in adulthood. For example, denervated hindpaws did not grow to a normal size (Fig. 2), and were held in a characteristic manner, with the lateral toes curled inward toward the sole. Because of loss of sciatic motor fibers and small muscle mass, the denervated hindlimb was not as effective in supporting the animal and denervated hindpaws were often more or less dragged or used to push with during locomotion. The diminished size of the denervated hindpaw and hindlimb was also paralleled by a noticeable reduction in the gross diameter of the sciatic nerve and associated $\mathrm{L}_{6}, \mathrm{~L}_{5}$, and, to a lesser extent, $\mathrm{L}_{4}$ dorsal root ganglia and roots on the injured side (Fig. 3).

The sensory innervation to the denervated hindpaws of all 

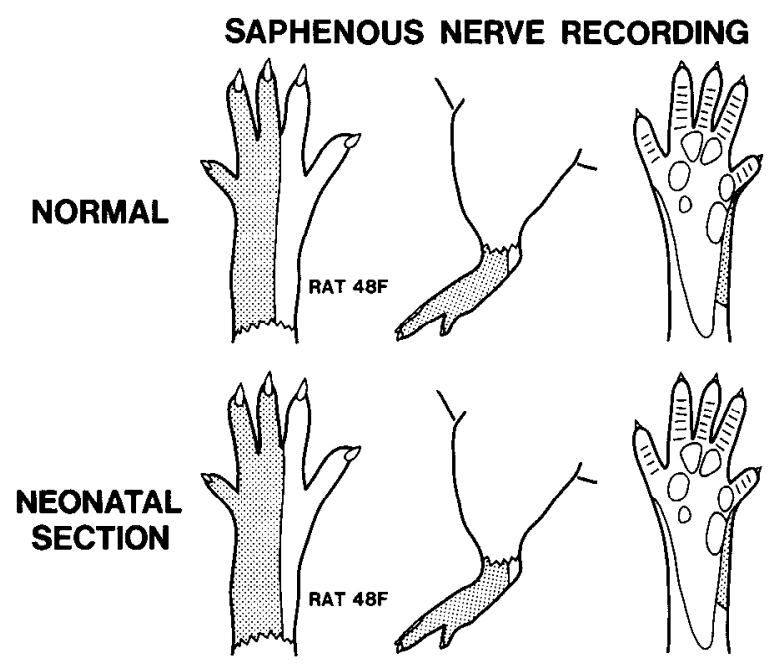

HINDPAW CORTEX RECORDING
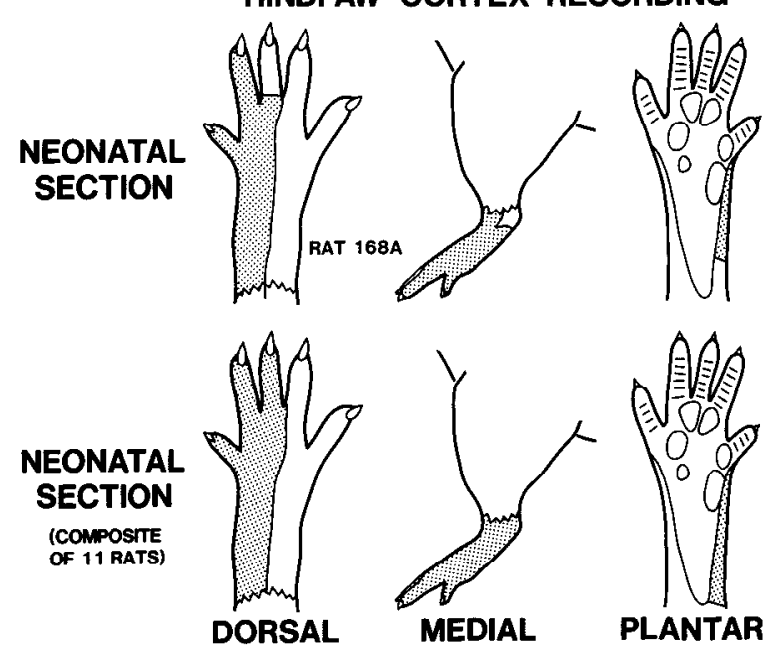

Figure 4. Composite receptive field areas (stippled) from which lowthreshold mechanosensory responses were evoked during recordings of the saphenous nerve (top two rows) or S-I hindpaw cortex (bottom two rows). Saphenous nerve composites compare innervation from the normal (row I) and denervated ( row 2) hindpaws of one rat. Cortical composites compare innervation from one rat (row 3) and the total group of 11 rats studied (row 4). The hindpaw skin area normally innervated by the saphenous nerve (e.g., row l) is similar to the skin area that remains innervated following neonatal sciatic denervation (bottom three rows), regardless of whether innervation is assessed by recordings of the saphenous nerve or the S-I cortex. Toe 1 is on the left in the dorsal view, centered in the medial view, and on the right in the plantar view of the hindpaw.

neonatally sectioned rats was assessed by cortical or peripheral nerve recordings to determine what parts of the hindpaw remained innervated. The results indicate that there was no reinnervation of the hindpaw by the sciatic nerve and no major sprouting of low-threshold saphenous fibers into the denervated sciatic skin territory. For example, the hindpaw skin is normally innervated by the saphenous and sciatic nerves. Each nerve has a highly consistent innervation territory and, for low-threshold mechanoreceptor afferents, there is little $(<1 \mathrm{~mm})$ or no overlap across the borders of these territories (Wall and Cusick, 1984). In normal adult rats, the saphenous nerve innervates the hairy skin on toes 1-3 and the dorsomedial hindpaw, whereas the sciatic nerve innervates the remaining hairy skin on the toes and dorsolateral hindpaw and the plantar skin (e.g., Fig. 4, top row, and Fig. 1 in Wall and Cusick, 1984). The surviving in-
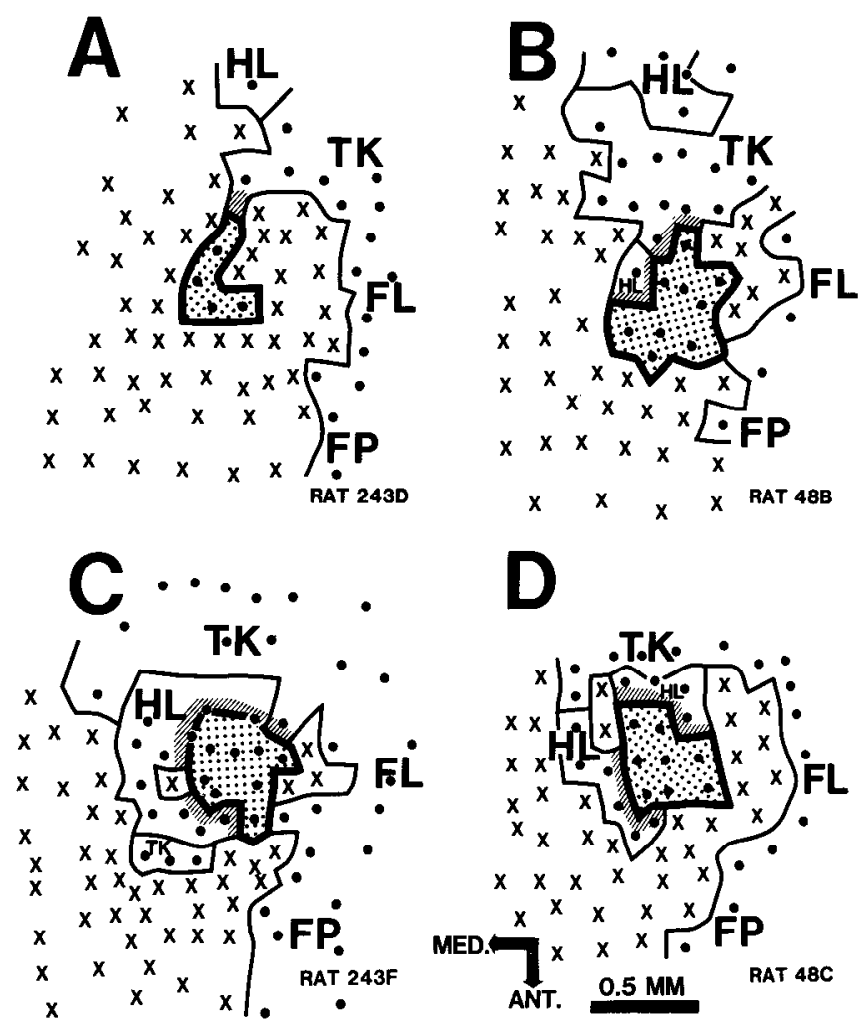

Figure 5. The S-I representation of mechanosensory inputs from the hindpaw (stippled region surrounded by heavy border) and adjacent body regions in four adult rats that had undergone transection of the sciatic nerve on the day of birth. Dots, Cortical sites where cutaneous responses were recorded; $x$ 's, sites not responsive to cutaneous stimuli. The spatial calibration and orientation indicated in $D$ applies also to $A-C$. Abbreviations and other conventions as in Figure 1.

nervation to the hindpaws of neonatally denervated rats was determined by examining the locations of all cortical receptive fields on the hindpaw and by constructing a composite skin area covercd by thesc ficlds. The composite of all cortical receptive fields on the hindpaw of one representative rat and the composite for the entire group of 11 neonatal denervates is shown at the bottom of Figure 4. All cortical fields on denervated hindpaws were located on hairy skin of toes 1-3 and the dorsomedial hindpaw. The hindpaw innervation was further studied by direct recordings from low-threshold mechanosensory fibers in the saphenous nerves of two adult rats that had been neonatally denervated. The composites of all saphenous nerve fields on both the denervated and normal hindpaws of one animal are shown at the top of Figure 4. A comparison of the top and bottom parts of Figure 4 indicates that there is a close match between the hindpaw skin that activated neurons in the S-I hindpaw representation and the hindpaw skin territory innervated by the saphenous nerve. In addition, the saphenous territory on denervated hindpaws closely resembles the normal saphenous territory. These findings indicate that the peripheral innervation deficits produced in the immature hindpaws were maintained into adult life.

\section{Organization in $S-I$ cortex}

Following neonatal sciatic transection, the developing representation of the hindpaw in the S-I cortex retains inputs from the saphenous nerve but is deprived of its sciatic inputs. In describing the cortical consequences of neonatal denervation, we consider (1) the cortical representation of noninjured hindpaw inputs from the saphenous nerve, (2) the cortical zone deprived of hindpaw inputs from the sciatic nerve, (3) the pat- 


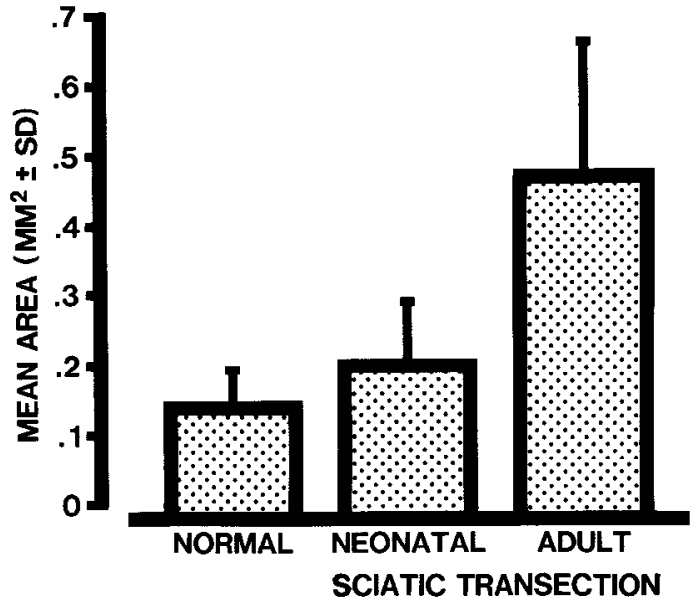

Figure 6. Mean area of S-I cortex representing hindpaw skin innervated by the saphenous nerve in normal adult rats (left; $n=10)$ and in adult rats that had undergone transection of the sciatic nerve on the day of birth (middle; $n=11$ ) or during adulthood (right; $n=7$ ). Bars, 1 SD.

tern of topographical organization produced in the hindpaw and adjacent representations, and (4) the overall size of the cutaneously responsive zone in the hindpaw cortex.

The representation of hindpaw inputs from the saphenous nerve

Cortical location. In all neonatal denervates, the saphenous skin territory on denervated hindpaws was represented in a relatively constant position in the S-I cortex (Fig. 5). This representation was rostral to representations of the hindlimb and/or trunk, medial to the representation of the forelimb, and caudomedial to the representation of the forepaw. In addition, portions of the medial, lateral, and rostral borders of the hindpaw representation were immediately adjacent to cortical zones that were not responsive to cutaneous stimuli (Fig. 5). In normal adult rats, inputs from hindpaw skin arcas innervated by the saphenous nerve typically project to the lateral and more caudal part of the hindpaw representation (e.g., Fig. $1 B$ ). The relative location of this representation with respect to representations of neighboring body parts has been described in detail (Wall and Cusick, 1984) and, on the basis of the localizing features described above, the representation of the saphenous hindpaw territory in neonatally denervated rats was very similar to the location of this representation in normal adult rats (e.g., Figs. $1 B$ and 5). These findings indicate that establishment of saphenous projections in a normal cortical locus does not depend on the presence of inputs from adjacent parts of the hindpaw during the neonatal period.

The location of the saphenous hindpaw representation in neonatally denervated rats was also very similar to the location of the saphenous hindpaw representation in rats that underwent sciatic transection as adults (e.g., Figs. $1 C$ and 5; Wall and Cusick, 1984). Thus, the saphenous hindpaw representation maintains a relatively normal cortical location after sciatic section at different postnatal ages.

Size measures. The cortical area responsive to saphenous inputs from the hindpaw was measured in all neonatally denervated rats and compared to similar measures from normal rats and rats denervated as adults. This comparison indicated that sciatic transection in neonatal and adult rats had different effects on the size of the representation of hindpaw inputs from the saphenous nerve. For example, the mean area of the saphenous representation in neonatally denervated rats (Fig. 6, middle) was slightly larger but not significantly different $(t[19]=1.82$, $p>0.05$ ) from the mean area of this representation in normal

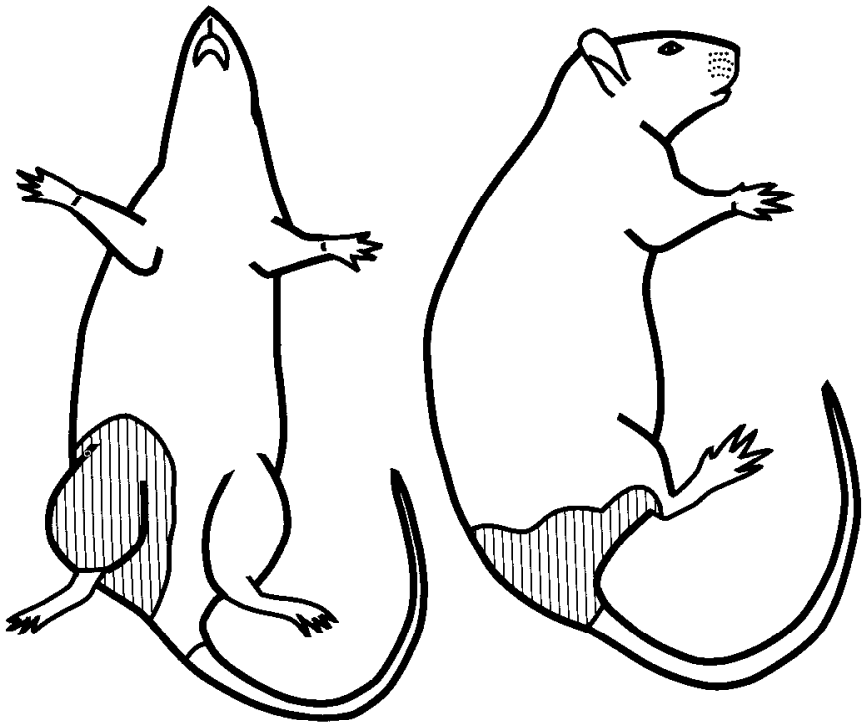

Figure 7. Composite receptive field areas (hatched) of penetrations that were located in the deprived cortex, mediorostral to the representation of hindpaw inputs from the saphenous nerve. Most fields were on the medial hindlimb and adjacent pelvic-abdomen trunk region indicated on the left.

rats (Fig. 6, left). In contrast, the mean area of the saphenous representation in neonatal denervates was noticeably smaller than the mean size of this representation in rats that were chronically denervated during adulthood (Fig. 6, right), and this difference was statistically significant $(t[16]=3.86, p<0.01)$. These findings indicate that neonatal injury precludes the development of a saphenous hindpaw representation on the order of size of the expanded representation seen after adult injury.

\section{The cortical zone deprived of sciatic inputs from the hindpaw}

The cortical representation of hindpaw skin innervated by the sciatic ncrve is normally located immediately mediorostral to the representation of hindpaw inputs from the saphenous nerve (Wall and Cusick, 1984; e.g., Fig. 1B). To assess the effects of neonatal denervation in this deprived cortex, an evaluation was made of the response properties of neurons recorded at all penetrations that were mediorostral to the saphenous hindpaw representation and that would normally fall within the area receiving sciatic nerve inputs. Two major changes were apparent in the deprived cortical zone: (1) Neurons recorded in some penetrations showed no evoked activity to cutaneous stimuli, while (2) neurons at other penetrations had abnormally located cutaneous receptive fields. The extent to which these changes were seen varied from animal to animal. In $45 \%(5 / 11)$ of the rats, neurons recorded at every or almost every penetration in the deprived cortical zone were unresponsive to cutaneous stimuli (e.g., Fig. 5, $A, B$ ). In the remaining $55 \%$ of the rats, abnormal cutaneous representations were found along the mediorostral edge of the representation of saphenous inputs from the hindpaw (e.g., Fig. $5, C, D$ ). In effect, neonatal denervation appeared to produce a graded pattern of cortical change that ranged from complete loss of cutaneous responsiveness in the deprived cortex to variable establishment of cutaneous inputs.

The peripheral locations of cutaneous inputs to the deprived cortex were studied in each animal by examination of the receptive field areas defined at all penetrations located mediorostral to the representation of saphenous hindpaw inputs and in an area of cortex comparable to the normal representation of hindpaw inputs from the sciatic nerve. Figure 7 summarizes this information in views of the composite skin areas covered by these fields in all neonatally denervated rats. Most receptive 


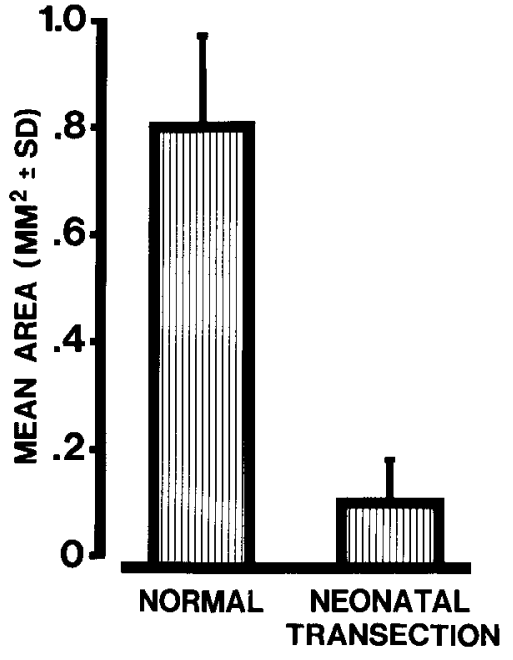

Figure 8. Mean areas of S-I cortex representing (left) hindpaw skin innervated by the sciatic nerve in normal adult rats $(n=10)$ and (right) proximal hindquarter skin in the deprived hindpaw zone of adult rats that had undergone transection of the sciatic nerve on the day of birth $(n=11)$. Bars, $1 \mathrm{SD}$.

fields $(79 \%, 31 / 39)$ were located on the medial surface of the hindlimb or on the adjacent pelvic-abdomen trunk region (Fig. 7 , left), while the remaining fields were on the posterior margin of the hindlimb or adjacent trunk (Fig. 7, right). Since the representation of saphenous inputs from the hindpaw was nearly normal in size, inputs from the hindpaw did not reoccupy the deprived cortical zone to any major extent.

The cutaneous inputs from the hindquarter to the deprived cortex were not due to anomalous reinnervation of the hindquarter by regenerated sciatic fibers. Dissections of the hindlimbs after mapping indicated that the sciatic nerve stumps terminated in neuromas that were encased in scar tissue adhering to surrounding muscles. Although careful dissections under microscopic view indicated no major regencration, it could be argued that it is difficult to completely eliminate the possibility that some sensory fibers reinnervated the skin and went unnoticed. To test this possibility, the sciatic nerve in three neonatally denervated rats was resectioned proximal to the neuroma immediately before mapping, to eliminate any possible regenerated inputs. Two of these rats had abnormal hindquarter representations in the deprived cortex (Fig. $5 D$ is taken from one of these rats) while, in the third rat, the deprived cortex was unresponsive to cutaneous stimuli. These findings indicate that the graded patterns of change in the deprived cortex were not dependent on peripheral regeneration of sciatic fibers.

Measurements were made of the cutaneously responsive cortical area located mediorostral to the saphenous hindpaw representation in neonatal denervates in order to study the extent of the deprived cortex that became occupied by proximal hindquarter inputs. The representation of the hindpaw skin innervated by the sciatic nerve in normal rats can serve as an estimate of the area of hindpaw cortex that becomes deprived after sciatic transection. In normal adult rats, this representation occupies a mean cortical area of about $0.8 \mathrm{~mm}^{2}$ (Fig. 8, left; Wall and Cusick, 1984). The mean size of the mediorostral responsive area in neonatal denervates equaled about $12 \%$ of the representation of sciatic hindpaw inputs in normal rats (Fig. 8, right). This decrease in size from normal was statistically significant $(t[19]=11.67, p<0.001)$. These findings suggest that cutaneous inputs from the proximal hindquarter of neonatal denervates occupied a relatively small part of the cortical zone that would normally be activated by sciatic nerve inputs from the hindpaw.
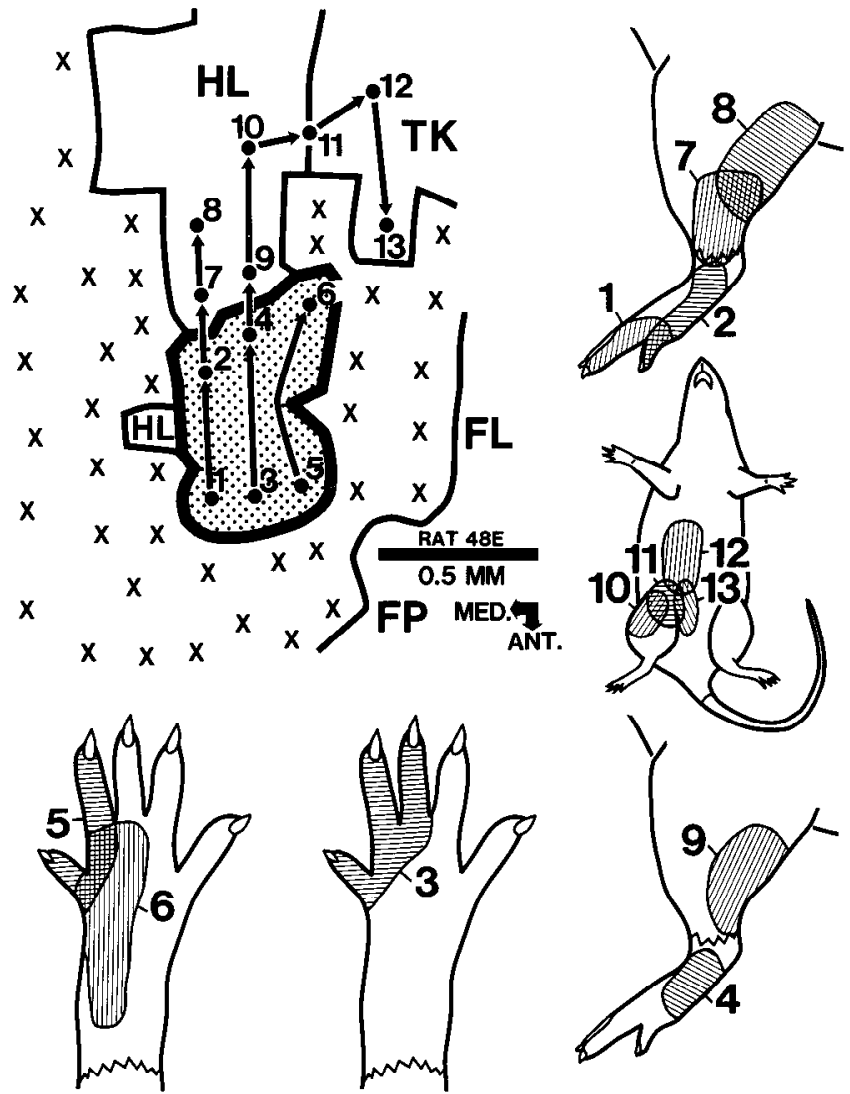

Figure 9. Topographical organization in the cortical representation of the hindpaw (stippled with heavy border) and neighboring body parts of a neonatally denervated adult rat. Upper left, Map of the hindpaw and adjacent cortex. Numbered dots, Locations of some of the recording sites in this experiment. $\times$ 's, Sites not responsive to cutaneous stimulation. Arrows link cortical sites with fields on the hindpaw, hindlimb $(I I L)$, and trunk $(T K)$. Other conventions as in Figure 1. Right and bottom, Receptive field locations of numbered recording sites indicated in the cortical map. Note that (1) within the hindpaw representation, rostrocaudal shifts in cortical sites (arrows) correspond to distal-proximal shifts in receptive field location on the hindpaw, whereas, for cortical shifts in the mediolateral direction, there was more overlap in receptive fields; and (2) there was a topographical progression of receptive field shifts for recording sites across the hindpaw, hindlimb, and trunk representations.

\section{Topographical organization in the hindpaw and adjacent hindlimb and trunk representations}

We were interested in determining whether topographical changes were produced in cortex when postnatal development occurred with an incomplete set of peripheral inputs. An assessment was therefore made of the internal topographical organization of the hindpaw representation and of the topographical linkages between the hindpaw and adjacent hindlimb and trunk representations.

Internal topography of the hindpaw representation. Despite a lifelong denervation of much of the hindpaw, the topographical organization in the representation of surviving hindpaw inputs in neonatal denervates was normal in many respects. For example, in normal rats there is an internal topographical order in the hindpaw representation (Wall and Cusick, 1984). The topography is somewhat coarse, in that receptive fields at neighboring penetrations usually overlap extensively; however, with larger movements across cortex, receptive field centers are observed to shift systematically across the hindpaw skin. The hindpaw representation is generally polarized such that rostral to 

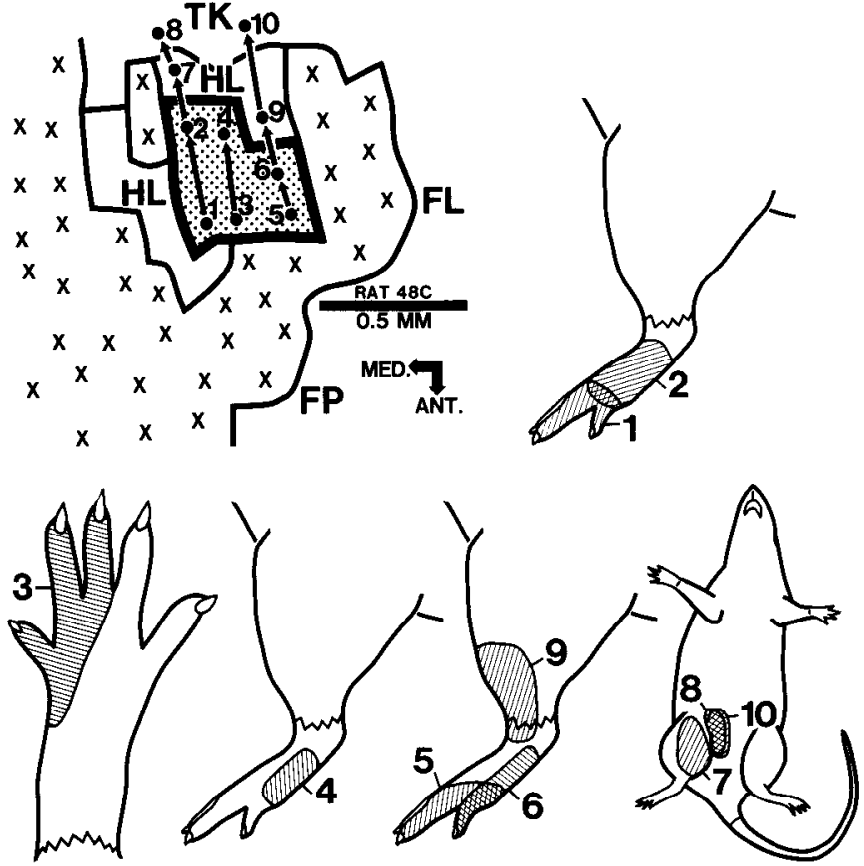

Figure 10. Topographical organization in the cortical representation of the hindpaw (stippled with heavy border) and neighboring body parts of a neonatally denervated adult rat. Conventions and description as in Figure 9.

caudal movements across cortex correspond to distal to proximal shifts across the hindpaw, while lateral to medial cortical movements relate to medial to lateral field shifts across the hindpaw. The topographical organization in the representation of the saphenous inputs from hindpaws of neonatally denervated rats was similar to that seen in normal rats. Receptive fields at neighboring cortical sites showed variable degrees of partially shifted overlap. With larger cortical movements in a rostrocaudal direction, there was a tendency for field centers to shift from distal to proximal parts of the hindpaw (Fig. 9, recording and receptive field sites $1-6$; Fig. 10, recording and receptive field sites 1-6; Fig. 11, recording and receptive field sites $1-3$ ). It was difficult to demonstrate systematic shifts across the mediolateral axis of the hindpaw representation of neonatal denervates primarily because the saphenous skin field on the hindpaw is narrow in the mediolateral dimension and, given the size of the receptive fields, it was hard to detect shifts across the hindpaw
(Figs. 9 and 10). Similar intcrnal topography was scen in neonatal denervates regardless of the extent of cutaneous inputs in the adjacent deprived cortex (e.g., compare Figs. 9 and 10). These findings indicate that neonatal sciatic nerve injury did not upset the development of normal topographical organization patterns in the saphenous hindpaw system.

The topographical organization in the representation of hindpaw inputs from the saphenous nerve in neonatal denervates was also similar to the topography observed in rats denervated during adulthood (Wall and Cusick, 1984). This finding indicates that the internal patterns of topography in the saphenous system from the hindpaw are maintained following sciatic transection at any postnatal age.

Topographical interrelationships of the hindpaw, hindlimb, and trunk representations. Neonatal sciatic denervation deprived the mediorostral part of the hindpaw representation of normal inputs from the hindpaw. In some rats, this deprivation caused changes in the detailed topographical relationships of the representations of the proximal hindquarter and saphenousinnervated hindpaw skin. For example, the caudal border of the hind paw representation in normal adult rats is typically adjacent to the hindlimb representation or to the representations of the hindlimb and pelvis-abdomen trunk skin (e.g., Fig. $1 B$; Wall and Cusick, 1984); as a result, the $S$-I hindpaw representation is normally somatotopically linked to the remaining body representation through the adjacent representation of more proximal hindquarter inputs. Similar to normal rats, the caudal margin of the hindpaw representation in neonatally denervated rats also bordered the representations of the hindlimb and/or trunk (pelvis-abdomen). The detailed spatial relationships of these representations varied, however, from animal to animal: In 55\% (6/11) of the neonatal denervates, the caudal hindpaw representation primarily bordered the trunk (e.g., Figs. $5 A$ and 11 ); in $27 \%(3 / 11)$ it bordered both the trunk and hindlimb (e.g., Figs. $5 C$ and 13$)$; in the remaining $18 \%(2 / 11)$ it primarily bordered the hindlimb (e.g., Fig. 9). This variability is somewhat unusual in that normal rats typically fall into the latter two categories, whereas a nearly complete caudal juxtaposition with the trunk representation is not usually seen. In neonatal denervates, where the hindlimb representation bordered the hindpaw representation, the topographical continuity in the representations of the hindpaw, hindlimb, and trunk was similar to that seen in normal rats (e.g., Fig. 9, penetrations and fields 2,7, and 8; 3, 4, and 9-13; Wall and Cusick, 1984). In contrast, in neonatal denervates in which the caudal border of the hindpaw representation was linked with the trunk representation, there appeared to be a more noticeable jump in receptive field loca-
Figure 11. Topographical organization in the cortical representation of the hindpaw (stippled with heavy border) and neighboring body parts of a neonatally denervated adult rat. Conventions as in Figure 9. Note that the rostrocaudal topography within the hindpaw representation is similar to that shown in Figures 9 and 10. In this rat, however, the hindpaw representation is largely separated from the representation of the hindlimb by the intervening representation of the trunk. As a result, there is a more marked shift in receptive field locations across most of the caudal border of the hindpaw representation.
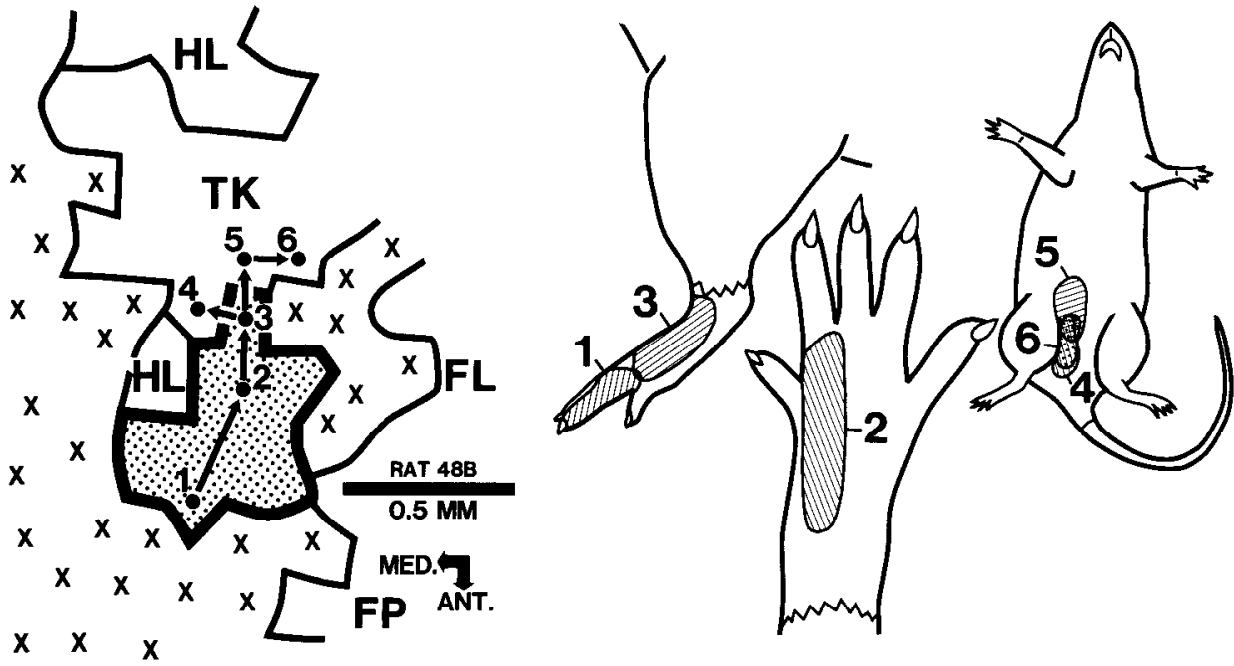

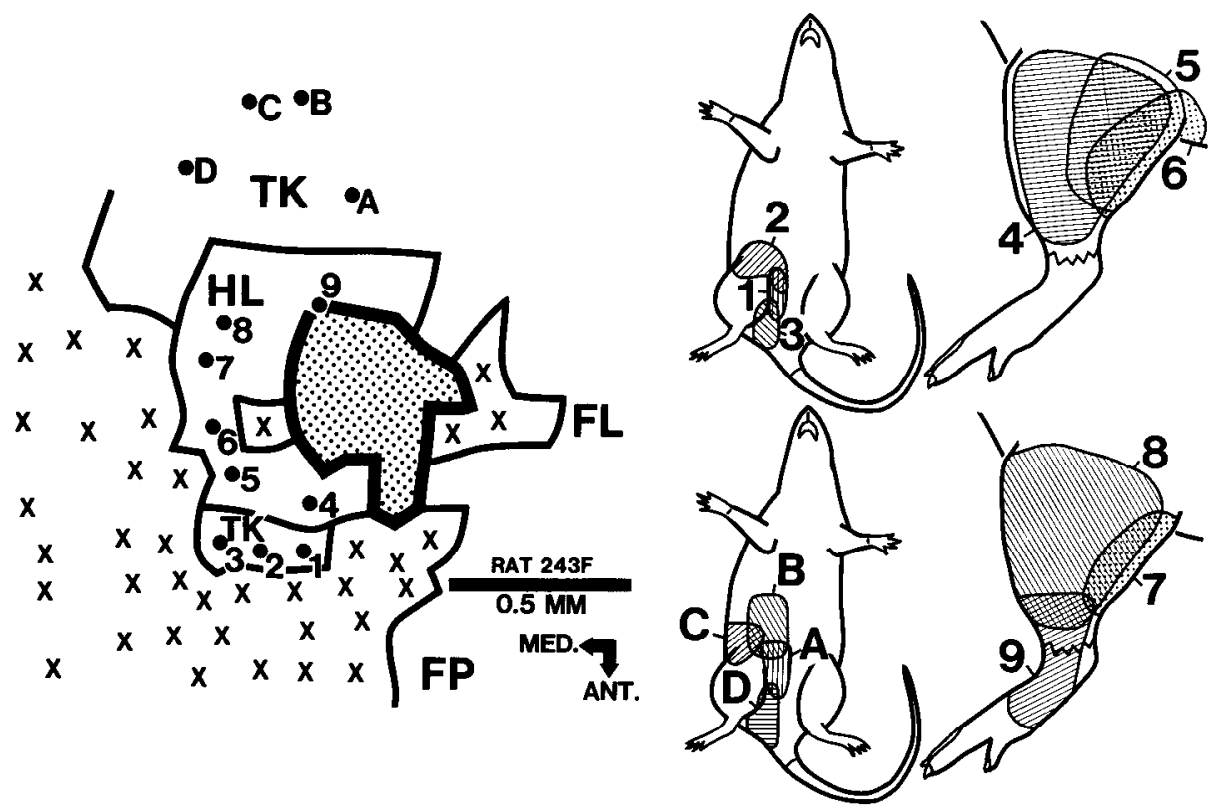

Figure 12. Examples of topographical "replications" and "shifts" in the deprived hindpaw cortex of a neonatally denervated adult rat. Left, Cortical map of the hindpaw (stippled with heavy border) and neighboring body parts, indicating some of the recording sites made in this experiment. Right, Receptive field locations of numbered and lettered recording sites indicated in the cortical map. Conventions as in Figure 9. Note that (1) cortical sites $1-3$ in the deprived cortical zone had trunk receptive fields that "replicated" receptive fields at cortical sites $A-D$, located about $1 \mathrm{~mm}$ morc caudally in the main rcpresentation of the trunk, and (2) the hindlimb representation appears to occupy a rostrally shifted position where hindpaw inputs from the sciatic nerve would normally be found. tions at neighboring cortical sites across this border (e.g., Fig. 11 , penetrations and fields 2-6). Some of these rats had hindlimb inputs to the deprived cortex, medial to the saphenous hindpaw representation. Even in these instances, however, the hindpaw representation did not appear to be normally linked to the trunk representation. Thus, in these rats there was little or no continuity in topographical organization across the border. These observations suggest that there were adjustments in the detailed topographical relationships of the hindpaw and more proximal hindquarter skin as a result of neonatal denervation. Such adjustments were not seen after sciatic transection in adult rats (Wall and Cusick, 1984).

These findings led us to question whether the representations in the deprived cortex resulted from rostral "shifts" in the representations of proximal hindquarter inputs, or whether the representations in deprived cortex were "replications" of representations that still occupied more normal locations caudal to the representation of saphenous inputs from the hindpaw. To study this issue, the receptive fields of neurons at all cortical sites in the deprived cortex were compared to receptive ficlds recorded at cortical sites caudal to the representation of saphenous inputs from the hindpaw. With topographical "shifts," fields in deprived cortex would not replicate caudal fields and a somewhat abnormally located but continuous representation might result, whereas with "replication," receptive fields in deprived cortex might extensively repeat fields seen more caudally and there might be a re-representation of inputs from the same skin. There was evidence that both "shifts" and "replication" occurred in the deprived cortex. For example, in the cortical representation of the neonatal denervate illustrated in Figure 12 , cortical sites $1-3$, rostral to the representation of hindpaw saphenous inputs, had highly abnormal receptive fields near the pelvic and abdomen regions of the trunk. These same skin regions were also represented approximately $1 \mathrm{~mm}$ more caudally at cortical sites in a more normal cortical location (Fig. 12, sites and fields A-D). The rostral fields in deprived cortex thus appeared to "replicate" the caudal fields. These "replicated" trunk representations were isolated from each other by an intervening representation of the hindlimb, which was mainly located medial to the hindpaw representation (Fig. 12, sites 4-9). In contrast to the abnormal "replication" of trunk fields in deprived cortex, this abnormal representation of hindlimb inputs appeared to extend in a continuous manner from the caudal margin of the hindpaw representation. Thus, these hindlimb inputs ap- peared to have shifted rostrally to some degree (compare with Figs. 9 and $1 B$ ). Replication of trunk and hindlimb fields was also seen in animals that had more limited cutaneous inputs to the deprived cortical zone (e.g., Fig. 13). These findings indicate that topographical linkages between the hindpaw and adjacent hindquarter representations were adjusted as a result of neonatal denervation and that replication and shifting of hindquarter inputs were two reflections of this adjustment.

\section{Estimates of the cutaneously responsive area in the hindpaw cortex}

Neonatal denervates did not recover cutaneous representations over a cortical area the size of the normal hindpaw representation. For example, in normal adult rats, the S-I representation of hindpaw skin innervated by the saphenous and sciatic nerves occupies a mean cortical area of $0.94 \mathrm{~mm}^{2}$ (Fig. 14, left; Wall and Cusick, 1984). In neonatal denervates, the mean area of cortex representing hindpaw inputs from the saphenous nerve and proximal hindquarter inputs in the deprived zone was 0.29

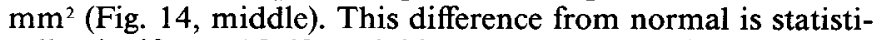
cally significant $(t[19]=10.32, p<0.001)$ and indicates that neonatal denervation resulted in a net loss of cutaneously activated cortex.

The cutaneously responsive area of hindpaw cortex in neonatal denervates was also not as extensive as in adult denervates. Following chronic transection of the sciatic nerve during adulthood, the cortical representation of saphenous inputs from the hindpaw occupies a mean area of $0.47 \mathrm{~mm}^{2}$ (Fig. 14, right; Wall and Cusick, 1984) and no cutaneous inputs are observed in cortex rostromedial to this representation. Thus, this area provides an estimate of the cutaneously responsive cortex comparable to the $0.29 \mathrm{~mm}^{2}$ area measure in neonatal denervates. The difference in the cutaneously responsive cortical areas in neonatal and adult denervates is small but statistically significant $(t[16]=2.57, p<0.05)$. This difference is not attributable to length of survival time after injury or other time-related factors such as adult age at mapping. For example, with chronic denervation of up to $160 \mathrm{~d}$ in adult rats that were at least $90 \mathrm{~d}$ old at injury, the total cortical area responsive to cutaneous inputs comprised about $50 \%$ of the normal hindpaw representation (Wall and Cusick, 1984). In neonatally sectioned rats with denervation times of $160-489 \mathrm{~d}$, the area was $28 \%$ of the normal hindpaw representation. Thus, neonatal denervates having postinjury times comparable to or longer than times in adults of 


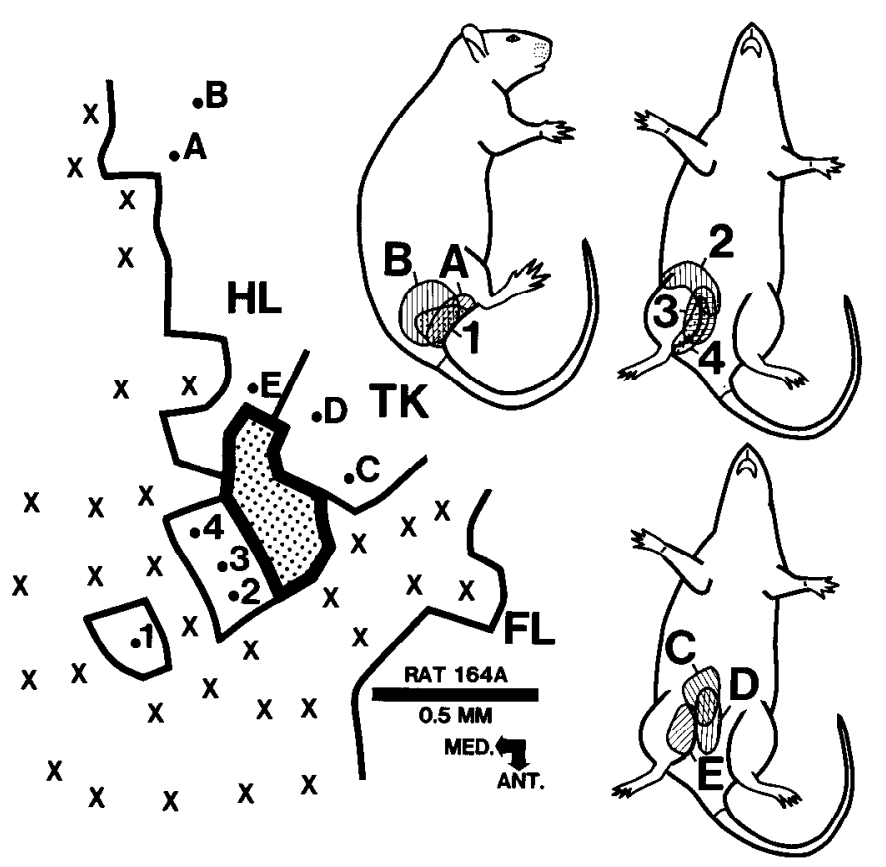

Figure 13. "Replications" in the deprived hindpaw cortex. Left, Cortical map of the hindpaw (stippled with heavy border) and neighboring body parts indicating some of the recording sites made in this experiment. Right, Receptive field locations of the numbered and lettered recording sites indicated in the cortical map. Conventions as in Figure 9. Note that the receptive fields of sites $1-4$ in the deprived cortical zone replicate receptive fields at sites $A-E$ located about $0.5-1.5 \mathrm{~mm}$ more caudally.

similar age at mapping still have a smaller cutaneously responsive area. Age at the time of nerve injury in these rats appears to be an important factor in determining the extent of cortical space that loses cutaneous activation.

\section{Discussion}

\section{Present findings}

The first goal of this study was to assess how the normal topographical map of the body surface in the primary somatosensory (S-I) cortex is affected when postnatal development occurs in the absence of inputs from part of the body. To study this issue, we compared the hindpaw representations of adult rats that developed postnatally with normal innervation of the hindpaw to the hindpaw representations of adult rats that developed postnatally with only saphenous innervation. Peripherally, neonatal transection and ligation of the sciatic nerve resulted in an irreversible loss of low-threshold mechanoreceptor inputs from the plantar and dorsolateral surfaces of the hindpaw (Fig. 15, top center, blackened). A comparison of the S-I maps in neonatal denervates and normal rats indicated that neonatal sciatic section resulted in the following cortical changes (Fig. 15, middle, left three panels): (1) The cortical representation of hindpaw skin innervated by the saphenous nerve in neonatal denervates was similar to that of normal rats in location, internal topographical organization, and size (Fig. 15, middle, stippling). (2) Two major changes were produced in the cortical zone deprived of sciatic inputs. In some neonatal denervates, small abnormal representations of cutaneous inputs from the proximal hindquarter were established (Fig. 15, middle, third panel from left, cross-hatching). In other denervates, no cutaneous inputs were apparent in this zone (Fig. 15, middle, second panel from left, blackened). (3) In animals that had hindquarter representations in the deprived zone, as well as in animals that did not, there

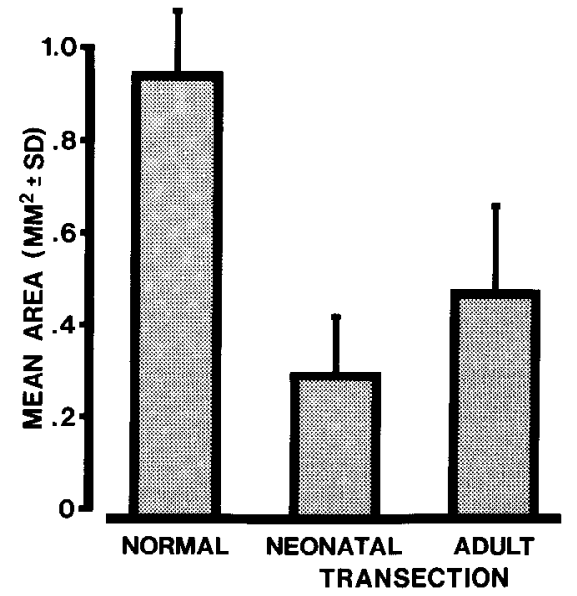

Figure 14. Mean area of S-I cortex representing (left) hindpaw inputs from the saphenous and sciatic nerves of normal adult rats $(n=10)$, (middle) hindpaw inputs from the saphenous nerve to normal cortex and hindquarter inputs to deprived cortex in adult rats that had undergone sciatic transection neonatally $(n=11)$, and (right) hindpaw inputs from the saphenous nerve to normal and deprived cortex in adult rats that had undergone sciatic transection during adulthood $(n=7)$. In the region of the hindpaw representation, there is a decrease in the size of the cutaneously responsive area after both neonatal and adult sciatic transection. In addition, the cutaneously responsive area is smaller after neonatal injury than after adult injury. Bars, $1 \mathrm{SD}$.

was a net loss of tactilely responsive cortex in the vicinity of the hindpaw representation (Fig. 15, middle, second and third panels, blackened). (4) Finally, the detailed topographical relationships between the representations of the hindpaw, hindlimb, and trunk were sometimes altered as a result of shifting and replication of hindlimb and trunk representations.

We conclude that loss of sensory inputs at birth caused lifelong changes in the functional organization of the body map in the S-I cortcx. Under the conditions of the present experiments, the general features of these changes were loss of the cortical representation of skin inputs from the injured nerve, increased variability in the detailed topographical relationships of representations of normally innervated skin regions near the denervated skin, decreased overall size of the S-I arca that was responsive to cutaneous stimuli, and partial infringement of the representations of normally innervated skin areas into the deprived cortex.

The second goal of this study was to evaluate the cortical effects of nerve injury at different ages. To study this issue, we compared the hindpaw representations of adult rats that had undergone sciatic transection and ligation on the day of birth to those of adult rats that had undergone sciatic transection and ligation during adulthood. In a previous study of sciatic transection in adult rats, the following major changes were seen (Wall and Cusick, 1984): (1) Peripherally, there was a sustained loss of low-threshold mechanoreceptor inputs from hindpaw skin areas innervated by the sciatic nerve (Fig. 15, top right, blackened). (2) In cortex, the representation of hindpaw saphenous inputs occupied a normal location but had expanded into parts of cortex where hindpaw sciatic inputs would normally be represented (Fig. 15, middle right, dense stippling). (3) Because of this expansion, about $40 \%$ of the cortical area deprived of sciatic inputs recovered cutaneous inputs. The remaining part of the deprived cortex, an area equal to about 40 $50 \%$ of the total hindpaw representation in normal rats, did not recover cutaneous inputs even after denervation of up to 5 months (Fig. 15, middle right, blackened).

The consequences of sciatic injury in adults were similar to 

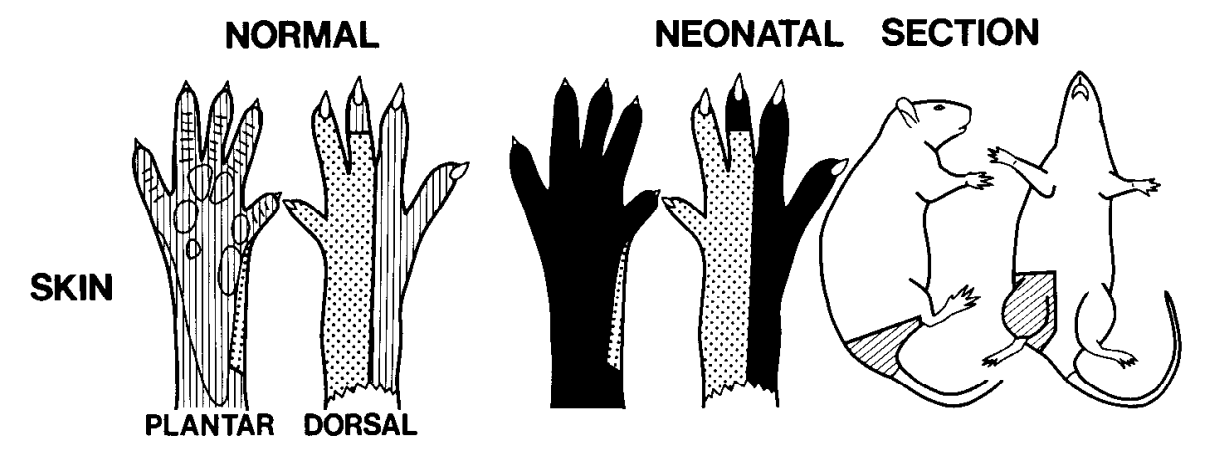

ADULT SECTION
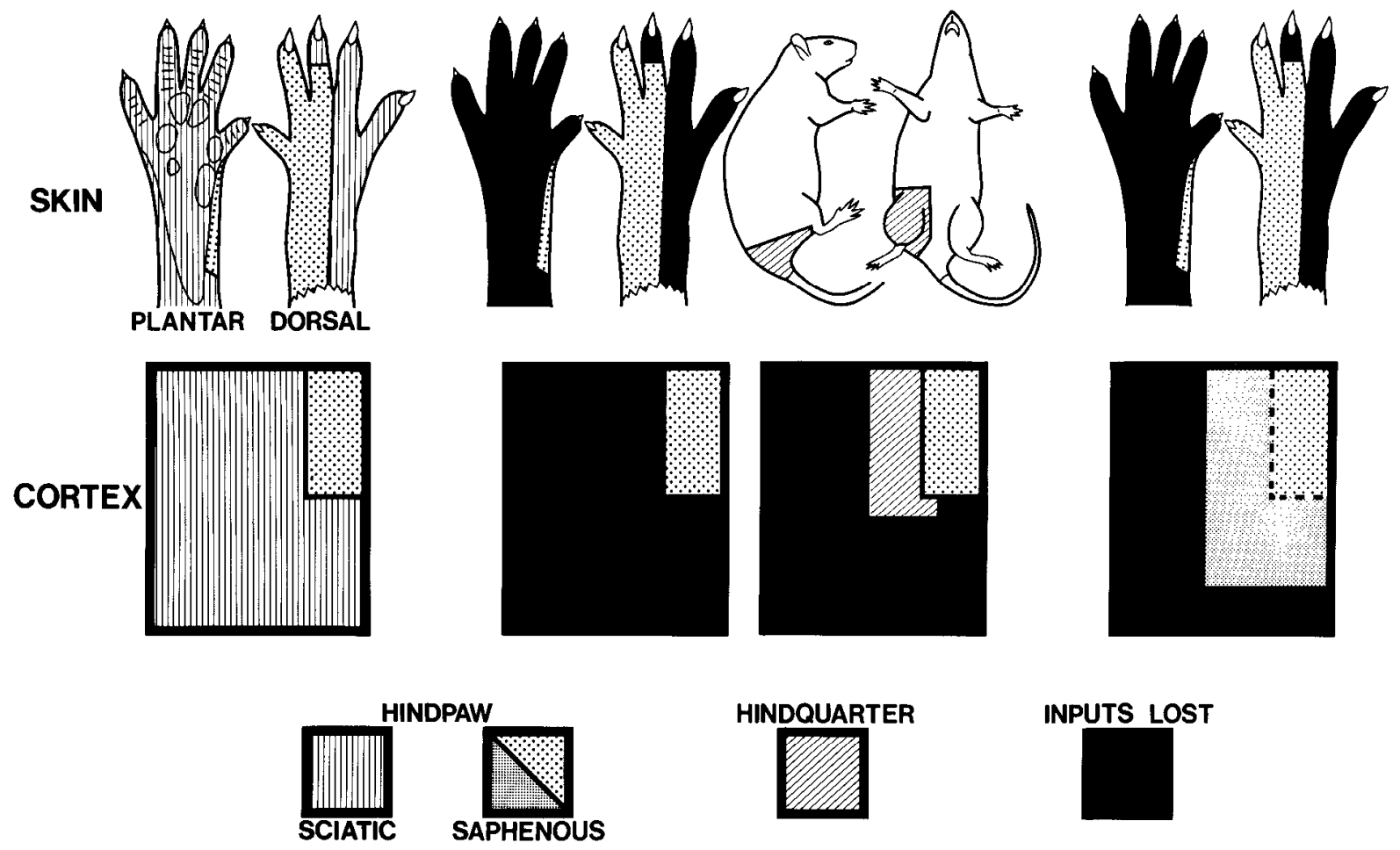

HINDPAW

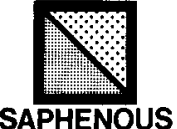

HINDQUARTER

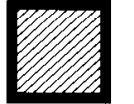

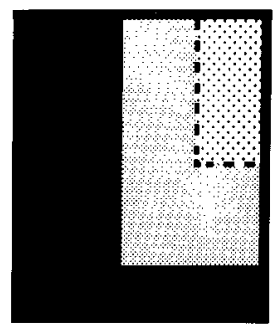

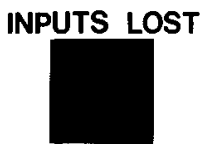

Figure 15. Schematic summary of the hindpaw system of normal adult rats (left) and adult rats after partial denervation of the hindpaw by sciatic section on the day of birth (center) or during adulthood (right). Peripheral changes are indicated along the top row, whereas corresponding changes in the S-I hindpaw cortex are indicated in the middle row. The bottom row provides a key to shading. See Discussion for details.

the present observations in the following respects: (1) The peripheral effect of injury at both times was a sustained loss of low-threshold inputs from the sciatic hindpaw skin (Fig. 15, top center and right, blackened). (2) In adult denervates and some neonatal denervates, cutaneous inputs from normally inncrvated skin areas were observed in parts of the cortical zone deprived of sciatic inputs from the hindpaw (Fig. 15, middle, hatching in third panel from left and dense stippling in right panel). (3) Finally, injury at both times resulted in a net loss of cutaneously responsive cortex in the vicinity of the hindpaw representation (Fig. 15, middle, blackened areas in right panel and second and third panels from left).

There were also notable differences in the consequences of adult and neonatal sciatic transection. (1) The organization in the deprived cortex of neonatal denervates varied such that some animals recovered substitute proximal hindlimb inputs whereas other animals did not recover cutaneous inputs (Fig. 15 , middle, second and third panels from left). Both these patterns differed from the consistent pattern of substitution from hindpaw inputs seen in adult denervates (Fig. 15, middle, right panel). (2) The topographical relationships of the hindpaw, hindlimb, and trunk representations in neonatal denervates were more variable and, in some instances, differed from the pattern seen in adult denervates. (3) The representation of saphenous inputs from the hindpaws of neonatal denervates was not enlarged like the representation of adult denervates but, instead, was similar in size to that of normal rats (Fig. 15, stippling in middle four panels). (4) Finally, the area of deprived cortex that recovered cutaneous responsiveness was smaller after neonatal injury than after adult injury (Fig. 15, middle, hatching in third panel from left and dense stippling in right panel).

Regarding the second question concerning the age-linked consequences of sciatic injury, these observations suggest that the general cortical reaction to peripheral injury in neonates and adults was similar: Some parts of the deprived cortex became reactivated by substitute inputs, whereas other parts lost cutaneous responsiveness. Age at injury did have an effect, however, on the cortical pattern of representation that was produced. For the rat hindpaw system, the major age-related changes involved differences in the skin locations from which substitute cutaneous inputs were derived and differences in the spatial extent of cortex that recovered cutaneous responsiveness.

We were surprised to find that the representation of hindpaw inputs from the saphenous nerve did not expand after neonatal denervation, as it had after adult denervation. From the initial findings in adults, a reasonable expectation was that neonatal animals would have fewer "constraints" than adults and, as a result, the representation of hindpaw inputs from the saphenous nerve might expand into all the deprivcd cortex and be on the order of size of the total hindpaw representation in a normal animal. This expectation reflected a general bias-that the nervous systems of young animals have better recovery capacities than adults (e.g., see Finger and Stein, 1982, and Simons and Finger, 1984, for discussion). The present finding that the representation of saphenous hindpaw inputs in neonatal denervates is smaller than that of adult denervates is not in line with this expectation. Even if hindquarter inputs to the deprived cortex are considered in neonatal denervates, the reactivated hindpaw cortical area is still not larger than that seen in adult denervates. We suggest that the nervous system of neonatal rats may be more "plastic" than the adult, but that this plasticity results in the young system being, in effect, more vulnerable to injury. In particular, injury of sciatic neurons in neonates may have a detrimental effect on the assembly of central circuits that are developmentally dependent on sciatic inputs at the time of injury (see below). This effect could preclude expansion of the hindpaw saphenous representation beyond the limit seen in neonatal denervates. 


\section{Extension of a dominant input hypothesis to the present findings}

The topographical organization of the hindpaw representation in normal adult rats indicates that about $80 \%$ of the hindpaw representation is dominantly activated by skin regions innervated by the sciatic nerve, while about $20 \%$ is dominantly activated by hindpaw skin innervated by the saphenous nerve (Fig. 15, middle left). In the previous study of sciatic section in adult rats (Wall and Cusick, 1984), the enlargement in the representation of hindpaw inputs from the saphenous nerve occurred rapidly, and it was hypothesized that peripheral injury altered the functional dominance of inputs to the hindpaw cortex in several ways. First, the cortical zone receiving dominant inputs from hindpaw skin innervated by the saphenous nerve continued to respond to these inputs ("saphenous" cortex; Fig. 15 , middle, left and right panels, light stippling). Next, a second cortical zone that normally received dominant inputs from the sciatic nerve lost and failed to recover cutaneous responsiveness ("sciatic" cortex; Fig. 15, middle right panel, blackened). Finally, an intervening zone between the "saphenous" cortex and the "sciatic" cortex received inputs from both nerves but, under normal conditions, was functionally dominated by sciatic inputs. Following sciatic transection, this dominance was switched and saphenous inputs became dominant input substitutes for lost sciatic inputs. As a result, this convergence zone became the area into which the saphenous representation expanded ("convergence" cortex; Fig. 15, middle right panel, dense stippling).

This framework for conceptualizing the functional projection zones of peripheral nerves in adult rats can be usefully applied to the present findings to provide the following picture of how early injury may interact with the initial development of normal cortical projection zones of nerves and with the development of normal topographical order in cortical representations.

First, the representation of hindpaw inputs from the saphenous ncrve in neonatal denervates was similar to the "saphenous" cortex in location, internal topographical organization, and size (Fig. 15, middle left three panels, light stippling). This suggests that cortical areas with dominant inputs from a single nerve can develop normally, independent of either normal peripheral inputs from neighboring nerves or normal activation of adjacent cortical areas. The present findings further indicate a net loss of cutaneously responsive cortex medial and rostral to the saphenous hindpaw representation in neonatal denervates. This suggests that at least some parts of the "sciatic" cortex did not recover substitute cutaneous inputs (Fig. 15, middle, second and third panels from left, blackened). This loss of responsiveness is also consistent with there being some degree of independence in the development, or, in this instance, lack of development, of cortical representations dominated by different nerves. These findings imply that functional representations of delimited skin territories are capable of developing or not developing as somewhat autonomous units.

Second, following neonatal denervation, some animals did not recover cutaneous responsiveness in the cortical zone immediately medial and rostral to the saphenous cortex, whereas other animals had partial representations of hindquarter inputs in this zone (Fig. 15, middle, second and third panels, hatching and blackened). In the dominant input hypothesis, this zone would coextend spatially with the "convergence" cortex in adult denervates (Fig. 15, middle right panel, dense stippling). These findings suggest that loss of dominant nerve inputs to a convergence zone in the cortex of developing animals may have at least two effects on the functional organization of other cutaneous inputs to that zone. (1) Dominant input loss may retard initial development of a normally sized subdominant projection zone of noninjured nerves; i.e., in neonatal denervates, the representation of hindpaw inputs from the saphenous nerve was not as large as it was in rats that had a normal development but were denervated as adults. (2) Early input loss may result in a strengthening of projections from different inputs, i.e., proximal hindquarter inputs as seen after neonatal injury instead of hindpaw inputs as seen after adult injury.

An interesting question raised by these observations is, what is the relationship between development of functional somatotopic order in central representations and peripheral "groupings" of cutaneous inputs? From the present findings, it is plausible that the initial development of a somatotopic map entails assembly of many patch- or stripe-like cortical units, each of which may acquire internal order somewhat autonomously, perhaps as a result of spatial or temporal contiguity of ascending inputs from a group of peripheral sensory axons. Since sensory axons of a peripheral nerve normally innervate a continuous skin territory, a nerve could readily serve as one such peripheral grouping. Fascicles within nerves or nerve branches to delimited skin areas could serve a similar function for fractions of the innervation field of a nerve. Cortical units that are autonomous for a single nerve may be pieced together through cortical units that are more dependent on converging dominant and subdominant inputs from more than one nerve. In an anatomical sense, this view is consistent with the patchlike array of cellular and fiber aggregates seen in the S-I hindpaw cortex of normal rats (Chapin and Lin, 1984; Dawson and Killackey, 1984; Welker, 1976) and with the partial maintenance (and partial loss) of these patchlike arrays after sciatic transection in 1-d-old rats (Dawson and Killackey, 1984; see below). This view is also consistent with findings from the trigeminal system, where the fascicular organization in the infraorbital nerve contributes a framework for spatially organized projections to isomorphic cortical representations of the vibrissae (Erzurumlu and Killackey, 1983). Similar patch- or stripe-like patterns specific to different inputs are important organizational units in a variety of other central structures (e.g., see Constantine-Paton, 1982, for a recent discussion).

From the perspective of the peripheral nerves, we suggest that normal development of topographical order in the S-I hindpaw representation may be analogous to assembling a puzzle that has three pieces: a saphenous piece, a sciatic piece, and a sciaticsaphenous convergence piece. The nerve injury experiments in neonatal and adult animals make discrimination of these pieces possible because different functional consequences are produced in cortical pieces where injured inputs are developmentally important or functionally dominant to different degrees. In this system, a dominant skin "image" can develop or fail to develop in the saphenous and sciatic pieces independent of each other. The development of dominant and subdominant "images" in the convergence piece, however, requires both nerves. We suggest that normal topographical organization in the hindpaw map may emerge as a product of the internal order within each nerve's piece and of the order resulting from specific convergence of spatial information from both nerves centrally. This arrangement could enable the CNS to assemble one integrated, topographical "image" of inputs that arrive from a continuous skin sheet via two nerves, even though there is little or no spatial overlap in the peripheral innervation territories of the nerves.

\section{Previous studies of somatosensory changes after peripheral injury in young mammals}

Studies of functional changes in cortex. All previous studies of cortical organization after early peripheral injury in rodents have assessed changes in animals that had undergone denervation of the mystacial vibrissae pad (Table $1, A-D, G$, and $H$, columns 2-6), whereas investigations in other mammals involved denervation of limbs (Table 1 , studies $\mathrm{E}$ and F, columns 2-6).

Previous findings from rodents are similar to the present results in the following respects: First, following early damage of 
Table 1. Studies of functional changes in somatosensory cortex after peripheral injury in young mammals

\begin{tabular}{|c|c|c|c|c|c|c|c|c|c|}
\hline \multirow{2}{*}{\multicolumn{2}{|c|}{$\begin{array}{l} \\
\text { (1) } \\
\text { Study } \\
\end{array}$}} & \multirow[b]{2}{*}{$\begin{array}{l}(2) \\
\text { Animal }\end{array}$} & \multirow[b]{2}{*}{$\begin{array}{l}(3) \\
\text { Denervated } \\
\text { skin area }\end{array}$} & \multirow[b]{2}{*}{$\begin{array}{l}\text { (4) } \\
\text { Type of } \\
\text { denervation }\end{array}$} & \multirow[b]{2}{*}{$\begin{array}{l}\text { (5) } \\
\text { Age at } \\
\text { injury }\end{array}$} & \multirow[b]{2}{*}{$\begin{array}{l}(6) \\
\text { Denerva- } \\
\text { tion } \\
\text { period } \\
\end{array}$} & \multicolumn{3}{|c|}{ Change in deprived cortex } \\
\hline & & & & & & & $\begin{array}{l}(7) \\
\text { Abnormal } \\
\text { cutaneous } \\
\text { responsive- } \\
\text { ness } \\
\end{array}$ & $\begin{array}{l}\text { (8) } \\
\text { Changes in } \\
\text { somatotopy }\end{array}$ & $\begin{array}{l}(9) \\
\text { Loss of cutaneous } \\
\text { responsiveness }\end{array}$ \\
\hline (A) & Welt (1977) & Rat & $\begin{array}{l}1 \text { or } 2 \text { rows of } \\
\text { facial } \\
\text { vibrissae }\end{array}$ & $\begin{array}{l}\text { Follicle } \\
\text { cautery }\end{array}$ & $1 \mathrm{~d}$ & $\geq 120 \mathrm{~d}$ & Yes & $\begin{array}{c}\text { Delimited changes in } \\
\text { representations of } \\
\text { adjacent vibrissae }\end{array}$ & $\begin{array}{l}\text { Unresponsive } \\
\text { recording sites } \\
\text { in some cases }\end{array}$ \\
\hline (B) & $\begin{array}{l}\text { Killackey et al. } \\
\text { (1978) }\end{array}$ & Rat & $\begin{array}{l}1 \text { or } 2 \text { rows of } \\
\text { facial } \\
\text { vibrissae }\end{array}$ & $\begin{array}{l}\text { Follicle } \\
\text { cautery }\end{array}$ & $1 \mathrm{~d}$ & $60 d$ & Yes & $\begin{array}{l}\text { Delimited changes in } \\
\text { representations of } \\
\text { adjacent vibrissae } \\
\text { and mystacial pad } \\
\text { fur }\end{array}$ & $\begin{array}{l}\text { Some } \\
\text { unresponsive } \\
\text { sites }\end{array}$ \\
\hline (C) & $\begin{array}{l}\text { Waite and } \\
\text { Taylor (1978) }\end{array}$ & Rat & $\begin{array}{l}\text { All or most } \\
\text { facial } \\
\text { vibrissae }\end{array}$ & $\begin{array}{l}\text { Mystacial pad } \\
\text { cautery }\end{array}$ & $1 \mathrm{~d}$ & $\begin{array}{l}\text { 15-26 } \\
\text { weeks }\end{array}$ & Yes & $\begin{array}{l}\text { Notable changes in } \\
\text { representations of } \\
\text { nose, lip hairs, and } \\
\text { cheek }\end{array}$ & Not seen \\
\hline (D) & $\begin{array}{l}\text { Pidoux et al. } \\
(1979,1980)\end{array}$ & $\begin{array}{l}\text { Rat and } \\
\text { mouse }\end{array}$ & $\begin{array}{l}\text { All or most } \\
\text { facial } \\
\text { vibrissae }\end{array}$ & $\begin{array}{l}\text { Follicle } \\
\text { cautery }\end{array}$ & $\begin{array}{r}1 \mathrm{~d} \text { or } \\
20 \mathrm{~d}\end{array}$ & $\begin{array}{l}\leq 80-90 \\
\text { d }\end{array}$ & Yes & $\begin{array}{l}\text { Changes in } \\
\text { representations of } \\
\text { mystacial pad fur }\end{array}$ & Not seen \\
\hline (E) & $\begin{array}{l}\text { Kalaska and } \\
\text { Pomeranz } \\
(1979)\end{array}$ & Cat & $\begin{array}{l}\text { Forepaw below } \\
\text { wrist }\end{array}$ & $\begin{array}{l}\text { Nerve } \\
\quad \text { transection }\end{array}$ & $\begin{array}{r}1.5-3.0 \\
\text { weeks }\end{array}$ & $\begin{array}{l}\text { 8-10 } \\
\text { weeks }\end{array}$ & Yes & $\begin{array}{l}\text { Notable changes in } \\
\text { spatial distribution } \\
\text { of neurons } \\
\text { representing } \\
\text { forearm }\end{array}$ & $\begin{array}{l}\text { Increased } \\
\text { proportion of } \\
\text { unresponsive } \\
\text { neurons }\end{array}$ \\
\hline (F) & $\begin{array}{l}\text { Kelahan et al. } \\
(1981) ; \text { Carson } \\
\text { et al. }(1981)\end{array}$ & $\begin{array}{l}\text { Rac- } \\
\text { coon }\end{array}$ & Forepaw digit 3 & $\begin{array}{l}\text { Nerve } \\
\quad \text { transection }\end{array}$ & $2-8$ weeks & $\begin{array}{l}9-12 \\
\text { months }\end{array}$ & Yes & $\begin{array}{l}\text { Notable changes in } \\
\text { representations of } \\
\text { normally } \\
\text { innervated parts of } \\
\text { hand }\end{array}$ & $\begin{array}{l}\text { No large } \\
\text { unresponsive } \\
\text { zones }\end{array}$ \\
\hline (H) & Waite (1984) & Rat & $\begin{array}{l}\text { All facial } \\
\text { vibrissae and } \\
\text { lip hairs }\end{array}$ & $\begin{array}{l}\text { Nerve } \\
\quad \text { transection }\end{array}$ & $1 \mathrm{~d}$ & $60 \mathrm{~d}$ & Yes & $\begin{array}{l}\text { Increased size and } \\
\text { variability in } \\
\text { representations of } \\
\text { lower jaw, digits, } \\
\text { and vibrissae over } \\
\text { eyes and ears }\end{array}$ & Yes \\
\hline (I) & Present study & Rat & Part of hindpaw & $\begin{array}{l}\text { Nerve } \\
\quad \text { transection }\end{array}$ & $1 \mathrm{~d}$ & $\begin{array}{l}109-489 \\
\text { d }\end{array}$ & $\begin{array}{l}\text { Yes } \\
\quad(65 \% \text { of } \\
\text { animals })\end{array}$ & $\begin{array}{l}\text { Increased variability } \\
\text { in hindquarter } \\
\text { representation and } \\
\text { changes in } \\
\text { topographical } \\
\text { linkages }\end{array}$ & Yes \\
\hline
\end{tabular}

cutaneous inputs, all investigators have found that cortical neurons have some ability to recover responsiveness to noninjured cutaneous inputs (Table 1, column 7). Second, previous studies have indicated that changes in the cortical body map are primarily localized to cortical zones where inputs from the injured nerve are normally represented. Third, these changes involve inputs from normally innervated skin near the denervated skin and produce variability in the cortical representations of these normal inputs (Table 1, columns 3 and 8). Finally, most in- vestigators also found neurons in the deprived cortex that had no apparent cutaneous responsiveness long after injury (Table 1 , column 9). These similarities support the conclusion that early peripheral injury produces lifelong functional changes in parts of the somatosensory cortex that would normally be dependent on the injured inputs. For most studies, two features that consistently contribute to these changes are some decrease in cutaneous responsivity in cortex and some reordering of somatotopic specificities to produce a broadened variability in how 
the deprived part of the cortical map subsequently functions in processing cutaneous inputs.

The most notable difference between the present results and previous findings in young rodents concerns the degree of loss of cutaneous responsiveness in the deprived cortex. In most previous studies, peripheral injury involved cauterization of one or more rows of vibrissae follicles (Table 1, studies A-D and $\mathrm{G}$, column 4). The finding in these studies was that there was only a modest loss of cutaneous responsiveness (Table 1 , studies A, B, and G, column 9). In contrast, when the whole infraorbital nerve to the vibrissae was transected and ligated, larger unresponsive zones were common in the deprived vibrissae representation (Table 1, study $\mathrm{H}$, column 9). Thus, with respect to degree of loss of cutaneous responsiveness, the present findings are more consistent with previous observations from rodents with whole nerve transection injury.

Transection of whole nerves has also been used to study functional changes in the primary somatosensory cortex of young cats and raccoons. In contrast to rodents, the loss of cutaneous responsiveness in the deprived cortical zones of these animals appears to be relatively minor (Table 1 , studies $\mathrm{E}$ and $\mathrm{F}$, column 9). It is difficult, however, to compare findings because of the age disparities of these species. The animals studied in the cat and raccoon studies were not only older than the animals in the rodent studies (Table 1 , studies $\mathrm{E}, \mathrm{F}, \mathrm{H}$, and $\mathrm{I}$, column 5), but their somatosensory systems were more developed at the time of injury. For example, it is known that somatotopic maps exist in the S-I cortex of cats at birth (Rubel, 1971). Less has been reported about the initial appearance of cutaneous responses in the cortex of raccoons, but it is known that somatotopic maps are established at least prior to the second postnatal week (Kelahan and Doetsch, 1984). In rodents, thalamocortical projections are present in the white matter at birth, but invasion of the upper cortical plate first occurs over the next 2 or $3 \mathrm{~d}$ (Waite, 1977; Wise and Jones, 1978); consequently, the S-I cortex initially becomes responsive to peripheral electrical stimuli around the second or third postnatal day (Verley and Axelrad, 1975; Waite and Cragg, 1982) and to cutaneous stimuli around the sixth day (Armstrong-James, 1975). Thus, in the young cats and raccoons, nerve transection occurred after functional cortical maps had been established, whereas in rodents, nerve transection preceded normal functional activation of cortex. Thesc findings suggest that loss of cutaneous responsiveness in cortex may be greater for peripheral injuries that occur before cortical activation than for injuries that occur after initial activation.

Relationship between the present findings and previously defined anatomical changes after early injury. Previous studies in rodents have shown that neonatal peripheral injury affects the initial development of ascending anatomical connections between the facial vibrissae and the S-I cortex. In normal rodents, the vibrissae follicles are represented by spatially parcelled groups of neurons at brain stem, thalamic, and cortical levels of the trigeminal neuraxis (Belford and Killackey, 1979b; Erzurumlu et al., 1980; Ivy and Killackey, 1982; Killackey, 1973; Van der Loos, 1976; Woolsey and Van der Loos, 1970; Woolsey et al., 1979). Cauterization of follicles or injury of the infraorbital nerve during the first several postnatal days results in (1) loss of primary sensory neurons and disruption of the cellular organization in the trigeminal ganglion (Bates and Killackey, 1984; Durham and Woolsey, 1984; Erzurumlu and Killackey, 1982, 1983; Jacquin and Rhoades, 1983; Math et al., 1984; Rhoades et al., 1983; Savy et al., 1981; Waite, 1984; Waite and Cragg, 1979); (2) disorganization and shrinkage of brain stem trigeminal nuclei due to transynaptic loss of neurons (Waite, 1984); (3) abnormal spatial patterns of cells and fiber terminals at synaptic relays in the brain stem (Bates and Killackey, 1984; Bates et al., 1982; Belford and Killackey, 1979a, b, 1980; Durham and Woolsey, 1984; Erzurumlu and Killackey, 1983; Jacquin and Rhoades, 1983; Killackey and Shinder, 1981; Rhoades et al., 1983); thalamus (Belford and Killackey, 1979a, b, 1980; Durham and Woolsey, 1984; Killackey and Shindler, 1981; Woolsey et al., 1979) and S-I cortex (Belford and Killackey, 1980; Durham and Woolsey, 1984; Jeanmonod et al., 1977, 1981; Jensen and Killackey, 1984; Killackey and Belford, 1979 , 1980; Killackey et al., 1976; Van der Loos and Woolsey, 1973; Waite and Cragg, 1979; Weller and Johnson, 1975; Woolsey and Wann, 1976); and (4) alterations in the dendritic organization of cortical cells (Harris and Woolsey, 1979, 1981; Ryugo et al., 1975; Steffen and Van der Loos, 1980). These studies clearly indicate that the rodent somatosensory system is in a formative stage during the first several postnatal days and that spatial partitioning of connections involves an "outside-in" or peripheral-to-central sequence. The relative time relationships for partitioning at successively higher central levels of the system remain controversial, but there is agreement that the infraorbital nerve acts as a primary template for patterns at higher levels of the neuraxis (e.g., Durham and Woolsey, 1984; Erzurumlu and Killackey, 1982, 1983; Jeanmonod et al., 1981; Killackey, 1985; Van der Loos and Dorfl, 1978; Van der Loos and Welker, 1985). Neonatal peripheral injury disrupts this template and consequently the structural organization of ascending central connections undergoes an abnormal initial development.

Although studied less systematically, neonatal injury of spinal nerves causes anatomical changes along the neuraxis between the hindpaw and S-I cortex that resemble the trigeminal system changes. For example, injury of hindlimb nerves in young animals results in loss of primary sensory neurons (Aldskogius and Risling, 1981, 1983; Jorgensen and Dyck, 1979; Ranson, 1906; Risling et al., 1983; Yip and Johnson, 1984) and disorganization and shrinkage of the second-order nucleus gracilis (Johnson et al., 1972). Cellular barrels and segmented spatial patterns of axonal terminations like those seen in the S-I representation of the vibrissae have been shown in the S-I representation of the hindpaw in normal rats (Dawson and Killackey, 1984; Welker, 1976); interestingly, transection of the sciatic nerve on the day of birth in rats produces abnormal axonal termination patterns in the hindpaw cortex that resemble the disrupted patterns seen in the vibrissae cortex after injury of the infraorbital nerve (Dawson and Killackey, 1984). These findings suggest that the functional changes in the present study are, to some degree, attributable to altcrations in the spatial partitioning of ascending anatomical connections. The similarities in the hindpaw and vibrissae systems suggest that these partitioning changes result from an abnormal initial development of connections in components of the hindpaw system that, at the time of injury, were dependent on a peripheral template from the sciatic nerve.

Previous studies comparing the relative cortical effects of peripheral injury in young and adult mammals

Few studies have compared functional changes in cortex after peripheral injury in young and adult animals, and the studies that do exist contain major differences related to species (Table 2 , column 2), skin area denervated (column 3), and age at injury (columns 5 and 6). If these differences are overlooked, there is a general similarity in the cortical reactions to peripheral injury across studies. For example, regardless of age at injury, all studies have found that deprived cortical zones undergo some degree of reactivation by cutaneous inputs from normal nerves (Table 2 , column 7). On the other hand, as reflected by abnormally large proportions of neurons that were unresponsive to cutaneous stimuli, or by unresponsive cortical zones, there is also some agreement that nerve transection results in a loss of cutaneous responsiveness in cortex (Table 2, studies A, C, and D, column 7). These cortical reactions are generally consistent with findings from a larger body of studies dealing with cortical (for a recent review, see Kaas et al., 1983) and subcortical (Basbaum and Wall, 1976; Brinkhus and Zimmerman, 1983; Brown et al., 1983a, b; Devor and Wall, 1981a, b; Dostrovsky et al., 1976; 
Table 2. Studies comparing functional changes in cortex after peripheral injury in young and adult animals ${ }^{a}$

\begin{tabular}{|c|c|c|c|c|c|c|c|c|c|c|c|}
\hline \multirow{2}{*}{\multicolumn{2}{|c|}{$\begin{array}{l}\text { (1) } \\
\text { Study }\end{array}$}} & \multirow{2}{*}{$\begin{array}{l}(2) \\
\text { Animal }\end{array}$} & \multirow{2}{*}{$\begin{array}{l}(3) \\
\text { Denervated } \\
\text { skin area }\end{array}$} & \multirow{2}{*}{$\begin{array}{l}(4) \\
\text { Type } \\
\text { denervation }\end{array}$} & \multirow{2}{*}{$\begin{array}{l}\text { (5) } \\
\text { Age at } \\
\text { early } \\
\text { injury }\end{array}$} & \multirow{2}{*}{$\begin{array}{l}\text { (6) } \\
\text { Age at } \\
\text { late } \\
\text { injury }\end{array}$} & \multicolumn{4}{|c|}{$\begin{array}{l}\text { (7) } \\
\text { Cortical changes }\end{array}$} & \multirow{2}{*}{$\begin{array}{l}(8) \\
\text { Conclusions }\end{array}$} \\
\hline & & & & & & & Ear & ly injury & Lat & te injury & \\
\hline \multirow[t]{2}{*}{ (A) } & $\begin{array}{l}\text { Kalaska and } \\
\text { Pomeranz } \\
(1979)\end{array}$ & Cat & $\begin{array}{c}\text { Forepaw } \\
\text { below } \\
\text { wrist }\end{array}$ & $\begin{array}{l}\text { Nerve } \\
\text { tran- } \\
\text { section }\end{array}$ & $\begin{array}{r}1.5-3.0 \\
\text { weeks }\end{array}$ & $\begin{array}{l}>6 \\
\quad \text { months }\end{array}$ & (1) & $\begin{array}{l}52 \% \text { of } \\
\text { sampled cells } \\
\text { in deprived } \\
\text { cortex had } \\
\text { substitute } \\
\text { cutaneous } \\
\text { inputs }\end{array}$ & (1) & $\begin{array}{l}7 \% \text { of } \\
\text { sampled cells } \\
\text { had substitutc } \\
\text { cutaneous } \\
\text { inputs }\end{array}$ & $\begin{array}{l}\text { Recovery of } \\
\text { cutaneous } \\
\text { responsivencss } \\
\text { more limited } \\
\text { after adult } \\
\text { injury }\end{array}$ \\
\hline & & & & & & & (2) & $\begin{array}{l}19 \% \text { of } \\
\text { sampled cells } \\
\text { were } \\
\text { unresponsive } \\
\text { to cutaneous } \\
\text { stimuli }\end{array}$ & (2) & $\begin{array}{l}37 \% \text { of } \\
\text { sampled cells } \\
\text { were } \\
\text { unresponsive } \\
\text { to cutaneous } \\
\text { stimuli }\end{array}$ & \\
\hline \multirow[t]{2}{*}{ (B) } & $\begin{array}{l}\text { Kelahan et al. } \\
\text { (1981); Carson } \\
\text { et al. (1981); } \\
\text { Kelahan and } \\
\text { Doetsch (1984) }\end{array}$ & Raccoon & $\begin{array}{r}\text { Forepaw } \\
\text { digit } 3\end{array}$ & $\begin{array}{l}\text { Nerve } \\
\text { tran- } \\
\text { section }\end{array}$ & $\begin{array}{l}2-8 \\
\text { weeks }\end{array}$ & Adult & (1) & $\begin{array}{l}\text { Reactivation } \\
\text { of deprived } \\
\text { cortical zone }\end{array}$ & (1) & $\begin{array}{l}\text { Reactivation } \\
\text { of deprived } \\
\text { cortical zone }\end{array}$ & $\begin{array}{l}\text { (1) No age } \\
\text { difference in } \\
\text { extent of } \\
\text { recovery of } \\
\text { cutaneous } \\
\text { respon- } \\
\text { siveness }\end{array}$ \\
\hline & & & & & & & (2) & $\begin{array}{l}\text { No large } \\
\text { unresponsive } \\
\text { zones }\end{array}$ & (2) & $\begin{array}{l}\text { No large } \\
\text { unresponsive } \\
\text { zones }\end{array}$ & $\begin{array}{l}\text { (2) Receptive } \\
\text { fields of } \\
\text { substitute } \\
\text { cutaneous } \\
\text { inputs were } \\
\text { larger after } \\
\text { adult injury }\end{array}$ \\
\hline \multirow[t]{2}{*}{ (C) } & Waite (1984) & Rat & $\begin{array}{l}\text { All facial } \\
\text { vibrissae } \\
\text { and lip } \\
\text { hairs }\end{array}$ & $\begin{array}{l}\text { Nerve } \\
\text { tran- } \\
\text { section }\end{array}$ & $1 \mathrm{~d}$ & $60 d$ & (1) & $\begin{array}{l}\text { Extensive } \\
\text { reactivation of } \\
\text { deprived } \\
\text { cortical zone } \\
\text { by substitute } \\
\text { cutaneous } \\
\text { inputs }\end{array}$ & (1) & $\begin{array}{l}\text { Limited } \\
\text { reactivation of } \\
\text { deprived } \\
\text { cortical zone }\end{array}$ & $\begin{array}{l}\text { (1) Recovery of } \\
\text { cutaneous } \\
\text { respon- } \\
\text { siveness in } \\
\text { deprived } \\
\text { cortex more } \\
\text { limited in } \\
\text { extent after } \\
\text { adult injury }\end{array}$ \\
\hline & & & & & & & (2) & $\begin{array}{l}\text { Small } \\
\text { unresponsive } \\
\text { zones }\end{array}$ & (2) & $\begin{array}{l}\text { Large } \\
\text { unresponsive } \\
\text { zones }\end{array}$ & \\
\hline \multirow[t]{2}{*}{ (D) } & $\begin{array}{l}\text { Wall and } \\
\text { Cusick (1984); } \\
\text { present study }\end{array}$ & Rat & $\begin{array}{l}\text { Part of } \\
\text { hindpaw }\end{array}$ & $\begin{array}{l}\text { Nerve } \\
\text { tran- } \\
\text { section }\end{array}$ & $1 \mathrm{~d}$ & $>90 d$ & (1) & $\begin{array}{l}\text { Limited } \\
\text { reactivation of } \\
\text { deprived } \\
\text { cortical zone }\end{array}$ & (1) & $\begin{array}{l}\text { More } \\
\text { extensive } \\
\text { reactivation of } \\
\text { deprived } \\
\text { cortical zone }\end{array}$ & $\begin{array}{l}\text { (1) Recovery of } \\
\text { cutaneous } \\
\text { respon- } \\
\text { siveness in } \\
\text { deprived } \\
\text { cortex more } \\
\text { limited in } \\
\text { extent after } \\
\text { early injury }\end{array}$ \\
\hline & & & & & & & (2) & $\begin{array}{l}\text { Unresponsive } \\
\text { zones }\end{array}$ & (2) & $\begin{array}{l}\text { Unresponsive } \\
\text { zones }\end{array}$ & $\begin{array}{l}\text { (2) More } \\
\text { variability in } \\
\text { substitute } \\
\text { cutaneous } \\
\text { inputs after } \\
\text { early injury }\end{array}$ \\
\hline
\end{tabular}


Jacquin et al., 1984; Lisney, 1983; Marcus et al., 1984; Mendell et al., 1978; Millar et al., 1976; Pubols, 1984; Pubols and Goldberger, 1980; Sedivec et al., 1983; Waite, 1984) changes after peripheral injury in adult animals.

Although there is agreement that the cortical consequences of peripheral injury differ between young and adult mammals, it is difficult to identify a unifying concept that accurately encompasses the reported differences. One problem is that it is hard to compare the age-linked trends that have been observed. For example, in the present study and in a previous study in the rat, relatively large sectors of the deprived cortical zone were found to be unresponsive to cutaneous stimuli, and the size of these unresponsive zones varied with age at injury (Table 2, studies $\mathrm{C}$ and $\mathrm{D}$, column 7). In contrast, in cats and raccoons, unresponsive cortical zones were not prevalent, but age-linked differences involved more subtle features, such as the proportion of sampled neurons that were not responsive to cutaneous stimuli (Table 2, study A, column 7) or the receptive field size of neurons (Table 2 , study B, column 8 ). As was previously discussed, differences in system maturation at the time of injury probably contributed to these differences to some degree. Even when developmental disparities are better controlled, however, it still appears that age-linked cortical changes vary in major ways. For example, when results of rat studies are closely compared, recovery of substitute cutaneous inputs in the deprived hindpaw cortex was more limited (unresponsive zones were larger) after early sciatic injury, whereas recovery of cutaneous responsiveness in the vibrissa cortex was more limited (unresponsive zones were larger) after adult infraorbital injury (Table 2 , studies C, D, columns 7 and 8). Thus, the relative effects of injuring different nerves in young and adult rats can show an opposite trend. This difference is surprising, since these studies are similar in major ways: (1) injury involved transection of a whole nerve (column 4), (2) injury occurred at similar ages in young and adult animals (columns 5 and 6), (3) denervation was maintained for roughly similar periods of time, and (4) similar mapping and analytic methods were used. These observations suggest that age-linked trends in cortical reactivation vary as a function of different peripheral injuries.

There are other plausible reasons for suggesting that age-linked trends in cortical recovery vary as a function of the peripheral injury. With respect to young animals, if the previously discussed relationship between cortical reorganization and peripheral template disruption is correct, patterns of cortical recovery after early injuries could differ because of variable template disruptions after different injuries. Consistent with this line of thinking, the disruption in the spatial partitioning of cells and fibers at cortical levels after whole nerve transection differs from the disruption produced after cauterization of distal nerve endings (e.g., compare Durham and Woolsey, 1984; Jeanmonod et al., 1981; and Killackey and Belford, 1979, with Bates et al., 1982; Killackey and Shinder, 1981; and Rhoades et al., 1983). This difference appears to be related to the different consequences of these injuries on the central terminations of injured primary sensory fibers (e.g., Bates et al., 1982; Erzurumlu and Killackey, 1982; Killackey and Shinder, 1981). Cortical recovery after different injuries in adult animals can also vary. For example, cutaneous reactivation in the deprived cortical zone after sciatic nerve transection in adult rats (Wall and Cusick, 1984) appeared to be relatively more extensive than the reactivation observed after infraorbital nerve transection in adult rats (Table 2, study C). Similarly, variable degrees of cortical reactivation have been reported after transection of different nerves in other adult mammals (Merzenich et al., 1983a, 1984). The extent of the peripheral denervation appears to be an important factor in these findings.

The above observations suggest that age-related trends in cortical recovery after one injury may not always match the trend seen after a different injury. Age-related differences appear to reflect an interaction of the developmental maturity of the system at injury, and the nature or extent of the injury.

\section{Peripheral effects of denervation}

Previous studies in rats (Brenowitz and Devor, 1981; Devor et al., 1979; Greenfield and Devor, 1981; Jackson and Diamond, 1984; Nixon et al., 1984; Pomeranz and Markus, 1980; Wall and Cusick, 1984), cats (Horch, 1981), rabbits (Jackson and Diamond, 1983), and primates (Merzenich et al., 1983a, b; Wall et al., 1983) have shown that low-threshold mechanoreceptor fibers in intact nerves of adult animals do not sprout into adjacent, denervated skin zones. In contrast to these findings in adult animals, data on sprouting of normal low-threshold fibers after injury in young animals are less consistent. For example, following transection and ligation of the infraorbital nerve on the day of birth, Waite (1984) found that vibrissae normally innervated by this nerve remained denervated into adulthood. Similarly, Devor et al. (1979) noted that the lateral toes on the hindpaws of rats whose sciatic nerves were transected and ligated on the day of birth remained tactilely insensitive into adulthood. Somewhat different results have been reported in a recent study that described an age dependence in the sprouting capacity of low-threshold mechanoreceptor fibers to the trunk skin of rats (Jackson and Diamond, 1981, 1984). The main finding was that sprouting did not occur when denervation occurred 15-20 d postnatally, but was seen following denervation at either 5 or $10 \mathrm{~d}$ of age.

In the present experiments, peripheral axons in the saphenous nerves of denervated hindpaws and central neurons in the S-I hindpaw cortex had low-threshold tactile receptive fields that were localized to hindpaw areas normally innervated by the saphenous nerve. Although the present results rule out major sprouting, they primarily rely on between-limb comparisons of the saphenous skin territory in normal and denervated hindpaws. Using this type of comparison, it is possible that increases in the density of the terminal branches of saphenous axons, or small changes along the borders of the saphenous skin territory of about $1 \mathrm{~mm}$ or less, remaincd undetcetcd bccausc of the variability in normal hindpaws. However, the borders of the innervated hindpaw skin zone after neonatal sciatic denervation were comparable to the borders seen after denervation in adult rats (Wall and Cusick, 1984). We suggest that any sprouting that remained undetected in the present study did not result in significant reinnervation.

The present findings and previous studies of facial and hindpaw skin in rodents (Devor et al., 1979; Waite, 1984) indicate that early denervation does not induce sprouting of low-threshold mechanosensory fibers. The relationship of these findings to the results from the rat trunk skin remain unclear. The rats studied by Jackson and Diamond $(1981,1984)$ were at least 5 $\mathrm{d}$ old at injury, so it is not certain whether sprouting occurs in younger animals. In addition, sprouting in the trunk skin was limited by dermatomal and other factors. Since it is known that neonatal denervation has different effects on tactile receptors in trunk and hindpaw skin (Mills et al., 1984), it is also possible that sprouting may vary in different body regions because of differences in local factors that regulate nerve innervation territories.

After neonatal transection of the sciatic nerve, the sciatic nerve stump and its associated $\mathrm{L}_{4}-\mathrm{L}_{6}$ dorsal root ganglia and roots (Kaizawa and Takahashi, 1970; Peyronnard and Charron, 1982; Rodin et al., 1983; Wall and Devor, 1981; Wiley and Wall, 1983) were smaller than normal. This is consistent with reports of loss of sensory cell bodies in dorsal root ganglia after nerve injury in young mammals (Aldskogius and Risling, 1981, 1983; Jorgensen and Dyck, 1979; Ranson, 1906; Risling et al., 1983; Yip and Johnson, 1984) and with the proposition that 
the patterns of cortical change after neonatal sciatic injury involve alterations in the capacity of the injured nerve to support normal development of the ascending hindpaw projection system.

\section{Differences in mechanisms of adjustment in the hindpaw system after sciatic nerve injury in adult and neonatal rats} The cortical patterns of cutaneous activation differ after sciatic injury in adult and 1-d-old rats. Do different mechanisms of change account for these pattern differences?

In our previous study of sciatic transection in adult animals, cortical rearrangements occurred within $2 \mathrm{~d}$ after injury and were thereafter maintained with denervation times of up to 5 months (Wall and Cusick, 1984). Rapid changes similar to these cortical changes have been observed in the adult rat spinal cord after injury of hindlimb nerves (Devor and Wall, 1981 a; Markus et al., 1984; Wall and Devor, 1981), and at cortical and subcortical levels in other adult mammals (Dostrovsky et al., 1976; Jacquin et al., 1984; Kelahan and Doetsch, 1984; Metzler and Marks, 1979; Millar et al., 1976; Rasmusson and Turnbull, 1983), including primates (Merzenich and Kaas, 1982; Merzenich et al., 1983b), after a variety of peripheral injuries and manipulations. There is considerable evidence that normal cutaneous receptive fields do not fully reflect the wider range of inputs available to central somatosensory neurons (Chapin and Woodward, 1981; Devor and Wall, 1981b; Devor et al., 1977; Dostrovsky et al., 1977; Jacquin et al., 1984; Macgillis et al., 1983; Mendell et al., 1978; Merrill and Wall, 1972; Mountcastle, 1957; Wall and Werman, 1976). This implies that not all inputs converging on a cortical or other central neuron are equally successful in producing activation under different conditions (Wall, 1977). Given this possibility, it is plausible that rapid central reorganization after peripheral injury in adult rats entails functional modifications in preexisting connections (Devor, 1983; Merrill and Wall, 1978; Wall, 1975; Wall and Cusick, 1984).

As previously discussed, we suggest that the cortical patterns of functional organization after neonatal sciatic injury most likely involve anatomical modifications in the initial assembly of the ascending projection system to the hindpaw cortex. In contrast, the cortical patterns seen after adult sciatic injury involve, at least to some degree, functional changes in preexisting connections. The evidence for anatomical changes in the initial assembly of connections, on the one hand, and functional changes in preexisting connections, on the other, suggests that different. mechanisms underlie production of the specific patterns of cortical organization seen after neonatal and adult injuries.

\section{References}

Aldskogius, H., and M. Risling (1981) Effect of sciatic neurectomy on neuronal number and size distribution in the $\mathrm{L}_{7}$ ganglion of kittens. Exp. Neurol. 74: 597-604.

Aldskogius, H., and M. Risling (1983) Preferential loss of unmyelinated $\mathrm{L}_{7}$ dorsal root axons following sciatic nerve resection in kittens. Brain Res. 289: 358-361.

Armstrong-James, M. (1975) The functional status and columnar organization of single cells responding to cutaneous stimulation in neonatal rat somatosensory cortex S-I. J. Physiol. (Lond.) 246: 501-538.

Basbaum, A. I., and P. D. Wall (1976) Chronic changes in the response of cells in adult cat dorsal horn following partial deafferentation: The appearance of responding cells in a previously nonresponsive region. Brain Res. 116: 181-204.

Bates, C. A., and II. P. Killackey (1984) Changes in the pattern of trigeminal primary afferent terminations in the brainstem of the rat after peripheral manipulations. Soc. Neurosci. Abstr. 10: 1157.

Bates, C. A., R. S. Erzurumlu, and H. P. Killackey (1982) Central correlates of peripheral pattern alterations in the trigeminal system of the rat. III. Neurons of the principal sensory nucleus. Dev. Brain Res. 5: 108-113.

Belford, G. R., and H. P. Killackey (1979a) Vibrissae representation in subcortical trigeminal centers of the neonatal rat. J. Comp. Neurol. 183: 305-322.

Belford, G. R., and H. P. Killackey (1979b) The development of vibrissac representation in subcortical trigeminal centers of the nconatal rat. J. Comp. Neurol. 188: 63-74.

Belford, G. R., and H. P. Killackey (1980) The sensitive period in the development of the trigeminal system of the neonatal rat. J. Comp. Neurol. 193: 335-350.

Brenowitz, G. L., and M. Devor (1981) Reinnervation of rat glabrous hindpaw skin by collateral sprouts following denervation by sciatic nerve section. Anat. Rec. 199: 37A.

Brinkhus, H. B., and M. Zimmermann (1983) Characteristics of spinal dorsal horn neurons after partial chronic deafferentation by dorsal root transection. Pain 15: 221-236.

Brown, A. G., P. B. Brown, R. E. W. Fyffe, and L. M. Pubols (1983a) Effects of dorsal root section on spinocervical tract neurons in the cat. J. Physiol. (Lond.) 337: 589-608.

Brown, A. G., R. E. W. Fyffe, and M. J. Rowe (1983b) Effects of peripheral nerve section on dorsal horn somatotopy in the cat. $J$. Physiol. (Lond.) 339: 36P-37P.

Carson, L. V., A. M. Kelahan, R. H. Ray, C. E. Massey, and G. S. Doetsch (1981) Effects of early peripheral lesions on the somatotopic organization of the cerebral cortex. In Clinical Neurosurgery, P. W. Carmel, ed., pp. 532-546, Williams and Wilkins, Baltimore, MD.

Chapin, J. K., and C.-S. Lin (1984) Mapping the body representation in the S-I cortex of anesthetized and awake rats. J. Comp. Neurol. 229: 199-213.

Chapin, J. K., and D. J. Woodward (1981) Modulation of sensory responsiveness of single somatosensory cortical cells during movement and arousal behaviors. Exp. Neurol. 72: 164-178.

Constantine-Paton, M. (1982) The retinotectal hookup: The process of neural mapping. In Developmental Order: Its Origin and Regulation, S. Subtelny and P. B. Green, eds., pp. 317-349, Alan R. Liss, New York.

Dawsun, D. R., and H. P. Killackey (1984) Organization and modifiability of the cortical limb representations. Soc. Neurosci. Abstr. 10: 1156.

Devor, M. (1983) Plasticity of spinal cord somatotopy in adult mammals: Involvement of relatively ineffective synapses. In Nervous System Regeneration, B. Haber, J. R. Perez-Polo, G. A. Hashim, and A. M. Giuffrida Stella, eds., pp. 287-314, Alan R. Liss, New York.

Devor, M., and P. D. Wall (1981a) Plasticity in the spinal cord sensory map following peripheral nerve injury in rats. J. Neurosci. 1: 679684.

Devor, M., and P. D. Wall (1981b) Effect of peripheral nerve injury on receptive fields of cells in the cat spinal cord. J. Comp. Neurol. 199: 277-291.

Devor, M., E. G. Merrill, and P. D. Wall (1977) Dorsal horn cells that respond to stimulation of distant dorsal roots. J. Physiol. (Lond.) 270: $519-531$.

Devor, M., D. Schonfeld, Z. Seltzer, and P. D. Wall (1979) Two modes of cutaneous reinnervation following peripheral nerve injury. J. Comp. Neurol. 185: 211-220.

Donoghue, J. P., K. L. Kerman, and F. F. Ebner (1979) Evidence for two organizational plans within the somatic sensory-motor cortex of the rat. J. Comp. Neurol. 183: 647-664.

Dostrovsky, J. O., J. Millar, and P. D. Wall (1976) The immediate shift of afferent drive of dorsal column nucleus cells following deafferentation: A comparison of acute and chronic deafferentation in gracile nucleus and spinal cord. Exp. Neurol. 52: 480-495.

Dostrovsky, J. O., S. Jabbur, and J. Millar (1977) Anomalous connections in cat gracile nucleus. J. Physiol. (Lond.) 272: 38P-39P.

Durham, D., and T. A. Woolsey (1984) Effects of neonatal whisker lesions on mouse central trigeminal pathways. J. Comp. Neurol. 223: 424-447.

Erzurumlu, R. S., and H. P. Killackey (1982) Order in the developing rat trigeminal nerve. Dev. Brain Res. 3: 305-310.

Erzurumlu, R. S., and H. P. Killackey (1983) Development of order in the rat trigeminal system. J. Comp. Neurol. 213: 365-380.

Erzurumlu, R. S., C. A. Bates, and H. P. Killackey (1980) Differential organization of thalamic projection cells in the brain stem trigeminal complex of the rat. Brain Res. 198: 427-433.

Finger, S., and D. G. Stein (1982) Brain Damage and Recovery, Academic, New York.

Greenfield, Z., and M. Devor (1981) Collateral reinnervation of rat 
hindlimb skin does not depend on repeated sensory testing. Neurosci. Lett. 25: 305-309.

Hall, R. D., and E. P. Lindholm (1974) Organization of motor and somatosensory neocortex in the albino rat. Brain Res. 66: 23-38.

Harris, R. M., and T. A. Woolsey (1979) Morphology of Golgi-impregnated neurons in mouse cortical barrels following vibrissae damage at different post-natal ages. Brain Res. 161: 143-149.

Harris, R. M., and T. A. Woolsey (1981) Dendritic plasticity in mouse barrel cortex following postnatal vibrissa follicle damage. J. Comp. Neurol. 196: 357-376.

Horch, K. (1981) Absence of functional collateral sprouting of mechanoreceptor axons into denervated areas of mammalian skin. Exp. Neurol. 74: 313-317.

Ivy, G. O., and H. P. Killackey (1982) Ephemeral cellular segmentation in the thalamus of the neonatal rat. Dev. Brain Res. 2: 1-17.

Jackson, P. C., and J. Diamond (1981) Regenerating axons reclaim sensory targets from collateral nerve sprouts. Science 214: 926-928.

Jackson, P. C., and J. Diamond (1983) Failure of intact cutaneous mechanosensory axons to sprout functional collaterals in skin of adult rabbits. Brain Res. 273: 277-283.

Jackson, P. C., and J. Diamond (1984) Temporal and spatial constraints on the collateral sprouting of low-threshold mechanosensory nerves in the skin of rats. J. Comp. Neurol. 226: 336-345.

Jacquin, M. F., and R. W. Rhoades (1983) Central projections of the normal and "regenerate" infraorbital nerve in adult rats subjected to neonatal unilateral infraorbital lesions: A transganglionic horseradish peroxidase study. Brain Res. 269: 137-144.

Jacquin, M. F., R. D. Mooney, and R. W. Rhoades (1984) Altered somalosensory receptive fields in hamster colliculus after infraorbital nerve section and xylocaine injection. J. Physiol. (Lond.) 348: 471492.

Jeanmonod, D., F. L. Rice, and H. Van der Loos (1977) Mouse somatosensory cortex: Development of the alterations in the barrel field which are caused by injury to the vibrissal follicles. Neurosci. Lett. 6: $151-156$

Jeanmonod, D., F. L. Rice, and H. Van der Loos (1981) Mouse somatosensory cortex: Alterations in the barrel field following receptor injury at different early postnatal ages. Neuroscience 6: 1503-1535.

Jensen, K. F., and H. P. Killackey (1984) Infraorbital nerve section in newborn rat alters the terminal arbors of thalamocortical axons projecting to somatosensory cortex. Soc. Neurosci. Abstr. 10: 1156.

Johnson, J. I., T. C. Hamilton, J. Hsung, and P. S. Ulinski (1972) Gracile nucleus absent in adult opossums after leg removal in infancy. Brain Res. 38: 421-424.

Jorgensen, D., and P. J. Dyck (1979) Axonal underdevelopment from axotomy in kittens. J. Neuropathol. Exp. Neurol. 38: 571-578.

Kaas, J. H., M. M. Merzenich, and H. P. Killackey (1983) The reorganization of somatosensory cortex following peripheral nerve damage in adult and developing mammals. Annu. Rev. Neurosci. 6: 325-356.

Kaizawa, J., and I. Takahashi (1970) Fiber analysis of the lumbar spinal roots and their sciatic branches in rats. Tohoku J. Exp. Med. 100: $61-74$

Kalaska, J., and B. Pomeranz (1979) Chronic paw denervation causes an age-dependent appearance of novel responses from forearm in "paw cortex" of kittens and adult cats. J. Neurophysiol. 42: 618-633.

Kelahan, A. M., and G. S. Doetsch (1984) Time-dependent changes in the functional organization of somatosensory cerebral cortex following digit amputation in adult raccoons. Somatosensory Res. 2: 49-81.

Kelahan, A. M., R. H. Ray, L. V. Carson, C. E. Massey, and G. S. Doetsch (1981) Functional reorganization of adult raccoon somatosensory cerebral cortex following neonatal digit amputation. Brain Res. 223: 151-159.

Killackey, H. P. (1973) Anatomical evidence for cortical subdivisions based on vertically discrete thalamic projections from the ventral posterior nucleus to cortical barrels in the rat. Brain Res. 51:326331.

Killackey, H. P. (1985) Intrinsic order in the developing rat trigeminal system. In Development, Organization, and Processing in Somatosensory Pathways, M. Rowe and W. D. Willis, eds., pp. 43-51, Alan R. Liss, New York

Killackey, H. P., and G. R. Belford (1979) The formation of afferent patterns in the somatosensory cortex of the neonatal rat. J. Comp. Neurol. 183: 285-304.
Killackey, H. P., and G. R. Belford (1980) Central correlates of peripheral pattern alterations in the trigeminal system of the rat. Brain Res. 183: 205-210.

Killackey, H. P., and A. Shinder (1981) Central correlates of peripheral pattern alterations in the trigeminal system of the rat. II. The effect of nerve section. Dev. Brain Res. 1: 121-126.

Killackey, H. P., G. Belford, R. Ryugo, and D. K. Ryugo (1976) Anomalous organization of thalamocortical projections consequent to vibrissae removal in the newborn rat and mouse. Brain Res. 104: 309315.

Killackey, H. P., G. O. Ivy, and T. J. Cunningham (1978) Anomalous organization of SMI somatotopic map consequent to vibrissae removal in the newborn rat. Brain Res. 155: 136-140.

Lisney, S. J. W. (1983) Changes in the somatosensory organization of the cat lumbar spinal cord following peripheral nerve transection and regeneration. Brain Res. 259: 31-39.

Macgillis, M., R. Kang, D. Herman, and P. Zarzecki (1983) Interactions among convergent inputs to somatosensory cortex neurons. Brain Res. 276: 329-332.

Markus, H., B. Pomeranz, and D. Krushelnycky (1984) Spread of saphenous somatotopic projection map in spinal cord and hypersensitivity of the foot after chronic sciatic denervation in adult rat. Brain Res. 296: 27-39.

Math, M., B. G. Klein, and R. W. Rhoades (1984) Topographic representation of vibrissae follicles in the trigeminal (V) ganglion of normal adult rats and adults subjected to neonatal transection of the infraorbital (IO) nerve. Soc. Neurosci. Abstr. 10:1156.

Mendell, L. M., E. M. Sassoon, and P. D. Wall (1978) Properties of synaptic linkage from long ranging afferents onto dorsal horn neurones in normal and deafferented cats. J. Physiol. (Lond.) 285: 299-310.

Merrill, E. G., and P. D. Wall (1972) Factors forming the edge of a receptive field: The presence of relatively ineffective afferent terminals. J. Physiol. (Lond.) 226: 825-846.

Merrill, E. G., and P. D. Wall (1978) Plasticity of connection in the adult nervous system. In Neuronal Plasticity, C. W. Cotman, ed., pp. 97-111, Raven, New York.

Merzenich, M. M., and J. H. Kaas (1982) Reorganization of mammalian somatosensory cortex following peripheral nerve injury. Trends Neurosci. 5: 434-436.

Merzenich, M. M., J. H. Kaas, J. T. Wall, R. J. Nelson, M. Sur, and D. J. Felleman (1983a) Topographic reorganization of somatosensory cortical areas $3 b$ and 1 in adult monkeys following restricted deafferentation. Neuroscience $8:$ 33-55.

Merzenich, M. M., J. H. Kaas, J. T. Wall, M. Sur, R. J. Nelson, and D. J. Felleman (1983b) Progression of change following median nerve section in the cortical representation of the hand in areas $3 b$ and 1 in adult owl and squirrel monkeys. Neuroscience 10:639-665.

Merzenich, M. M., R. J. Nelson, M. P. Stryker, M. S. Cynader, A. Schoppmann, and J. M. Zook (1984) Somatosensory cortical map changes following digit amputation in adult monkeys. J. Comp. Neurol. 224: 591-605.

Metzler, J., and P. S. Marks (1979) Functional changes in cat somatic sensory-motor cortex during short term reversible epidural blocks. Brain Res. 177: 379-383.

Millar, J., A. I. Basbaum, and P. D. Wall (1976) Restructuring of the somatotopic map and appearance of abnormal neuronal activity in the gracile nucleus after partial deafferentation. Exp. Neurol. 50:658672.

Mills, L., C. A. Nurse, and J. Diamond (1984) Regional differences in the sensory nerve dependence of merkel cell development in rat skin. Soc. Neurosci. Abstr. 10: 1058.

Mountcastle, V. B. (1957) Modality and topographic properties of single neurons of cat's somatic sensory cortex. J. Neurophysiol. 20: $408-434$.

Nixon, B. J., R. Doucette, P. C. Jackson, and J. Diamond (1984) Impulse activity evokes precocious sprouting of nociceptive nerves into denervated skin. Somatosensory Res. 2: 97-126.

Peyronnard, J. M., and L. Charron (1982) Motor and sensory neurons of the rat sural nerve: A horseradish peroxidase study. Muscle Nerve 5: 654-660.

Pidoux, B., R. Verlcy, E. Farkas, and J. Scherrer (1979) Projections of the common fur of the muzzle upon the cortical area for mystacial vibrissae in rats dewhiskered since birth. Neurosci. Lett. 11: 301306.

Pidoux, B., M. F. Diebler, C. Savy, E. Farkas, and R. Verley (1980) 
Cortical organization of the postero-medial barrel-subfield in mice and its reorganization after destruction of vibrissal follicles after birth. Ncuropathol. Appl. Neurobiol. 6: 93-107.

Pomeranz, B., and H. Markus (1980) Peripheral sprouting of high threshold afferents in the saphenous nerve after sciatic nerve section in the rat. Soc. Neurosci. Abstr. 6: 658 .

Pubols, L. M. (1984) The boundary of proximal hindlimb representation in the dorsal horn following peripheral nerve lesions in cats: A reevaluation of plasticity in the somatotopic map. Somatosensory Res. 2: 19-32.

Pubols, L. M., and M. E. Goldberger (1980) Recovery of function in dorsal horn following partial deafferentation. J. Neurophysiol. 43: 102-117.

Ranson, S. W. (1906) Retrograde degeneration in the spinal nerves. J. Comp. Neurol. 16: 265-293.

Rasmusson, D. D., and B. G. Turnbull (1983) Immediate effects of digit amputation on SI cortex in the raccoon: Unmasking of inhibitory fields. Brain Res. 288: 368-370.

Rhoades, R. W., J. M. Fiore, M. F. Math, and M. F. Jacquin (1983) Reorganization of trigeminal primary afferents following neonatal infraorbital nerve section in hamster. Dev. Brain Res. 7: 337-342.

Risling, M., H. Aldskogius, and C. Hildebrand (1983) Effects of sciatic nerve crush on the $L_{\text {, }}$ spinal roots and dorsal root ganglia in kittens. Exp. Neurol. 79: 176-187.

Rodin, B. E., S. L. Sampogna, and L. Kruger (1983) An examination of intraspinal sprouting in dorsal root axons with the tracer horseradish peroxidase. J. Comp. Neurol. 215: 187-198.

Rubel, E. W. (1971) A comparison of somatotopic organization in sensory neocortex of newborn kittens and adult cats. J. Comp. Neurol. 143: 447-480.

Ryugo, D. K., R. Ryugo, and H. P. Killackey (1975) Changes in pyramidal cell density consequent to vibrissae removal in the newborn rat. Brain Res. 96: 82-87.

Sapienza, S., B. Talbi, J. Jacquemin, and D. Albe-Fessard (1981) Relationship between input and output of cells in motor and somatosensory cortices of the chronic awake rat. Exp. Brain Res. 43: 47-56.

Savy, C., S. Margules, E. Farkas-Bargeton, and R. Verley (1981) A morphometric study of mouse trigeminal ganglion after unilateral destruction of vibrissae follicles at birth. Brain Res. 217: 265-277.

Sedivec, M. J., J. Ovelmen-Levitt, R. Karp, and L. M. Mendell (1983) Increase in nociceptive input to spinocervical tract neurons following chronic partial deafferentation. J. Neurosci. 3: 1511-1519.

Simons, D., and S. Finger (1984) Some factors affecting behavior after brain damage early in life. In Early Brain Damage, Vol. 2, S. Finger

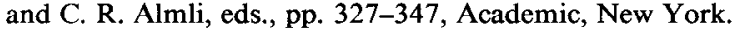

Simons, D. J., D. Durham, and T. A. Woolsey (1984) Functional organization of mouse and rat SmI barrel cortex following vibrissal damage on different postnatal days. Somatosensory Res. 1: 207-245.

Steffen, H., and H. Van der Loos. (1980) Early lesions of mouse vibrissal follicles: Their influence on dendrite orientation in the cortical barrel field. Exp. Brain Res. 40: 419-431.

Van der Loos, H. (1976) Barreloids in mouse somatosensory thalamus. Neurosci. Lett. 2: 1-6.

Van der Loos, H., and J. Dorfl (1978) Does the skin tell the somatosensory cortex how to construct a map of the periphery? Neurosci. Lett. 7: 23-30.

Van der Loos, H., and E. Welker (1985) Development and plasticity of somatosensory brain maps. In Development, Organization and Processing in Somatosensory Pathways, M. Rowe and W. D. Willis, eds., pp. 53-67, Alan R. Liss, New York.

Van der Loos, H., and T. A. Woolsey (1973) Somatosensory cortex: Structural alterations following early injury to sense organs. Science 179: 395-398.

Verley, R., and H. Axelrad (1975) Postnatal ontogenesis of potentials elicited in the cerebral cortex by afferent stimulation. Neurosci. Lett. 1: 99-104.

Waite, P. M. E. (1977) Normal nerve fibers in the barrel region of developing and adult mouse cortex. J. Comp. Neurol. 173: 165-174.
Waite, P. M. E. (1984) Rearrangement of neuronal responses in the trigeminal system of the rat following peripheral nerve section. $\mathbf{J}$. Physiol. (Lond.) 352: 425-445.

Waite, P. M. E., and B. G. Cragg (1979) The effect of destroying the whisker follicles in mice on the sensory nerve, the thalamocortical radiation, and cortical barrel development. Proc. R. Soc. Lond. [Biol.] 204: 41-55.

Waite, P. M. E., and B. G. Cragg (1982) The peripheral and central changes resulting from cutting or crushing the afferent nerve supply to the whiskers. Proc. R. Soc. Lond. [Biol.] 214: 191-211.

Waite, P. M. E., and P. K. Taylor (1978) Removal of whiskers in young rats causes functional changes in cerebral cortex. Nature 274 : 600-602.

Wall, J. T., and C. G. Cusick (1984) Cutaneous responsiveness in primary somatosensory (S-I) hindpaw cortex before and after partial hindpaw deafferentation in adult rats. J. Neurosci. 4: 1499-1515.

Wall, J. T., D. J. Fclleman, and J. H. Kaas (1983) Recovery of normal topography in the somatosensory cortex of monkeys after nerve crush and regeneration. Science 221: 771-773.

Wall, P. D. (1975) Are connections stable in adult mammalian brain? In Sensory Physiology and Behavior, R. Galun, ed., pp. 167-172, Plenum, New York.

Wall, P. D. (1977) The presence of ineffective synapses and the circumstances which unmask them. Phil. Trans. R. Soc. Lond. [Biol.] 278: 361-372.

Wall, P. D., and M. Devor (1981) The effect of peripheral nerve injury on dorsal root potentials and on transmission of afferent signals into the spinal cord. Brain Res. 209: 95-111.

Wall, P. D., and R. Werman (1976) The physiology and anatomy of long ranging afferent fibers within the spinal cord. J. Physiol. (Lond.) 255: 321-334.

Welker, C. (1971) Microelectrode delineation of fine grain somatotopic organization of SMI cerebral neocortex in albino rat. Brain Res. 26: 259-275.

Welker, C. (1976) Receptive fields of barrels in the somatosensory neocortex of the rat. J. Comp. Neurol. 166: 173-190.

Weller, W. L., and J. I. Johnson (1975) Barrels in cerebral cortex altered by receptor disruption in newborn, but not in five-day-old mice (Cricetidae and Muridae). Brain Res. 83: 504-508.

Welt, C. (1977) Physiological organization of the rat cortical barrel field following neonatal vibrissal damage. Soc. Neurosci. Abstr. 3: 494.

Wiley, R. G., and J. T. Wall (1983) Selective destruction of sciatic neurons using the suicide transport technique. Soc. Neurosci. Abstr. 9: 298.

Wise, S. P., and E. G. Jones (1978) Developmental studies of thalamocortical and commissural connections in the rat somatic sensory cortex. J. Comp. Neurol. 178: 187-208.

Woolsey, C. N. (1958) Organization of somatic sensory and motor areas of the cerebral cortex. In Biological and Biochemical Basis of Behavior, H. F. Harlow and C. N. Woolsey, eds., pp. 63-81, U. Wisconsin P., Madison, WI.

Woolsey, T. A., and H. Van der Loos (1970) The structural organization of layer IV in the somatosensory region (SI) of mouse cerebral cortex. The description of a cortical field composed of discrete cytoarchitectonic units. Brain Res. 17: 205-242.

Woolsey, T. A., and J. R. Wann (1976) Areal changes in mouse cortical barrels following vibrissal damage at different postnatal ages. J. Comp. Neurol. 170: 53-66.

Woolsey, T. A., J. R. Anderson, J. R. Wann, and B. B. Stanfield (1979) Effects of early vibrissae damage on neurons in the ventrobasal (VB) thalamus of the mouse. J. Comp. Neurol. 184: 363-380.

Yip, H. K., and E. M. Johnson (1984) Dorsal root ganglion neurons require trophic support from their central processes: Evidence for a role of retrogradely transported nerve growth factor (NGF) from the central to the peripheral nervous system. Soc. Neurosci. Abstr. 10: 368. 